Article

\title{
New Design of a CNG-H - -AIR Mixer for Internal Combustion Engines: An Experimental and Numerical Study
}

\author{
Hussein A. Mahmood ${ }^{1,2, *}$, Nor Mariah. Adam ${ }^{1}$, B. B. Sahari ${ }^{1}$ and S. U. Masuri ${ }^{1}$ \\ 1 Department of Mechanical and Manufacturing Engineering, Faculty of Engineering, \\ Universiti Putra Malaysia, 43400 UPM Serdang, Selangor, Malaysia; mariah@upm.edu.my (N.M.A.); \\ barkawi@upm.edu.my (B.B.S); ujila@upm.edu.my (S.U.M.) \\ 2 The Engineering Affairs Department, Presidency of the University of Baghdad, 999048 Baghdad, Iraq \\ * Correspondence: hussanadul@yahoo.com; Tel.: +60-1137470059
}

Received: 7 July 2017; Accepted: 5 September 2017; Published: 10 September 2017

\begin{abstract}
Several studies have aimed to convert diesel engines to dual- or tri-fuel engines to improve their fuel economy and reduce the emissions from diesel engine, however, most of these studies do not consider enhancing the homogeneity of fuel mixtures inside the engine and accurately controlling the air fuel ratio. In this study, a new air-fuel mixer was designed, manufactured and tested. The proposed air-gaseous fuel mixer design was conceived to be suitable for mixing air with compressed natural gas (CNG) and a blend of hydrogen and compressed natural gas (HCNG) that gives homogenous mixtures with high uniformity index and also to be easily connected with an Electronic Control Unit (ECU) for controlling accurately the air-gaseous fuel ratio for different engine speeds. For optimizing the homogeneity inside the new mixer, fourteen different mixer models were created to investigate the effects of diameter, location, and the number of holes inside the mixer on the homogeneity and distribution of the mixtures. Computational fluid dynamics analysis software was used to check the flow behavior, distribution and homogeneity of mixtures inside the new mixer models. The simulation results revealed that the best uniformity index (UI) values are obtained in model 7 where the UI values are 0.939 and 0.937 , respectively, for an air fuel ratio for a blend of hydrogen and compressed natural gas $(\mathrm{AFRHCNG})=51.31$ and the air fuel ratio for compressed natural gas $(\mathrm{AFRCNG})=34.15$. According to the numerical and experimental results for the new mixer (model 7) under different engine speeds (1000-4000) and air-CNG ratio of 34.15, a meaningful agreement is reached between the experimental and numerical values for AFRCNG (coefficient of determination $\left(R^{2}\right)=0.96$ and coefficient of variation $\left.(\mathrm{CoV})=0.001494\right)$.
\end{abstract}

Keywords: homogeneity of the mixture; air-CNG-hydrogen mixer; internal combustion engines; computational fluid dynamics (CFD)

\section{Introduction}

On- and off-road diesel engines are widely used for their high thermal efficiency and low hydrocarbon ( $\mathrm{HC}$ ) and carbon monoxide (CO) emissions, but they are major contributors of nitrogen oxide $\left(\mathrm{NO}_{\mathrm{x}}\right)$ and particulate matter $(\mathrm{PM})$ emissions. Various approaches for reducing $\mathrm{NO}_{\mathrm{x}}$ and $\mathrm{PM}$ emissions have been applied, including the use of selective catalytic reduction and diesel particulate filters, respectively. However, these two approaches depend heavily on the use of expensive precious metals as catalysts, and the devices are difficult to retrofit into in-use diesel vehicles. Accordingly, various compromise strategies have been proposed, including dual-fuel combustion [1-8].

Using gaseous fuels (alternative fuels) in diesel engines under the dual-fuel mode (diesel as the pilot fuel and gaseous fuels as the main fuel) offers an approach for reducing emissions and 
improving fuel economy. Moreover, dual-fuel engines allow the use of alternative fuels for cleaner combustion. The dual-fuel combustion strategy dramatically lowers the operational costs, extends the maintenance intervals and engine life, and reduces the emissions of $\mathrm{NO}_{\mathrm{x}}$ and soot [9]. In dual-fuel engines, the gaseous fuel (alternative fuel) is inducted along with the intake air and compressed like in a conventional diesel engine [6]. The mixture of air and gaseous fuel (CNG or HCNG) is ignited by injecting a small amount of liquid diesel fuel near the end of the compression stroke. Diesel fuel auto ignites and creates an ignition source for the surrounding air-gaseous fuel mixture. The pilot liquid fuel is injected using the conventional diesel injection equipment [5,10-17].

Among the various alternative fuels, natural gas (NG) is promising and highly attractive to the transportation sector [18-22]. First, NG is available in several areas worldwide at encouraging prices. Aside from oil and NG fields, the NG industry has been producing gas from increasingly more challenging resource types, such as sour gas, tight gas, shale gas, coal-bed methane, and methane gas hydrates. Second, although the main component of NG, namely, methane, is a greenhouse gas, NG remains an eco-friendly fuel. NG can contribute to the reduction of $\mathrm{CO}_{2}$ emissions because it exhibits the lowest carbon-to-hydrogen ratio of all the fossil fuels. NG can also substantially reduce $\mathrm{NO}_{\mathrm{x}}$ emissions and produce almost zero smoke and PM. Third, NG is not prone to knocking under normal circumstances because of its high methane number. Therefore, NG can be used in engines with relatively high compression ratios to obtain a higher thermal efficiency than that of a normal gasoline engine [22,23]. NG has been widely used in modern vehicles, and its application in diesel engine is normally in diesel-NG dual-fuel mode. Moreover, NG can be used in compression ignition engines under dual-fuel mode (diesel-NG engines).

The major advantages of dual-fuel NG-diesel engines include reduced $\mathrm{NO}_{\mathrm{x}}$ and $\mathrm{PM}$ emissions compared with those from diesel engines. However, the $\mathrm{CO}$ and $\mathrm{HC}$ (hydrocarbons) emission levels in compressed NG (CNG)-diesel engines are considerably higher than those in normal diesel engines. CNG-diesel engines also suffer from low brake thermal efficiency, low engine power, and low in-cylinder peak pressures and temperatures because the ignition delay under dual-fuel mode is long and the burning rate and flame propagation speed for CNG are slow [4-6,11,16,24-32].

Meanwhile, hydrogen is one of the most promising renewable fuels because it is naturally available, and it can be produced from various resources, such as fossil energy and biomass $[18,33]$. The addition of hydrogen in a compressed ignition engines under the dual-fuel mode can reduce $\mathrm{HC}, \mathrm{CO}$, and smoke emissions (PM). The combustion duration depends on the high-speed flame propagation of hydrogen in relation to other fuels. Injecting small amounts of hydrogen to a diesel engine can decrease the heterogeneity of a diesel fuel spray because of the high diffusivity of hydrogen, which makes the combustible mixture better and highly uniform $[34,35]$. The high homogeneity of the combustible mixture would provide good conditions for the complete combustion process, and fast combustion helps achieve constant volume, thereby increasing engine efficiency. The main disadvantages of using hydrogen as a fuel include combustion knock, high in-cylinder peak pressures and temperatures, high amounts of $\left(\mathrm{NO}_{\mathrm{x}}\right)$ emissions, and a high self-ignition temperature $[7,8,33,34,36-43]$.

Studies have recently focused on tri-fuel engines to increase the performance of conventional gas-diesel dual-fuel engines. Zhou et al. [44] conducted a series of in-depth experiments on the use of the hydrogen- $\mathrm{CH}_{4}$ mixture as the gaseous fuel in diesel engines along with the diesel fuel. The main results of this study showed that efficiency at low load at the $\mathrm{CH}_{4}$-diesel dual-fuel mode was enhanced by the addition of hydrogen. They also reported that the $\mathrm{CO} / \mathrm{HC}$ emissions and the $\mathrm{NO}_{\mathrm{x}}$ formation rate decreased when hydrogen and methane were added, respectively. Methane has a low flame propagation speed and minimal flammability, whereas hydrogen has extremely opposite characteristics. Thus, adding hydrogen can enhance the combustion process of methane, making it convenient in diesel engine applications. For the hydrogen-diesel dual-fuel mode, rapid burning rate, increased diffusivity, and reduced hydrogen ignition energy destabilizes the combustion, particularly at increased engine loads, which may result in knocking. Knocking is harmful to the mechanical durability 
and safety of engines. NG enrichment can stabilize and smoothen the combustion of hydrogen, thus avoiding knock or pre-ignition [44]. $\mathrm{NO}_{\mathrm{x}}$ emission is increased sharply with the addition of hydrogen because of the temperature [45-47]. High temperature in the combustion chamber during a relatively short, homogenous, premixed combustion leads to a high level of $\mathrm{NO}_{\mathrm{x}}$ formation rate. $\mathrm{NG}$ can lower the combustion temperature of hydrogen to repress the $\mathrm{NO}_{x}$ emissions $[35,44,47-50]$.

Installing a fuel-air mixer at the air inlet before the combustion chamber is one of the options that are used for modifying the diesel engine to accept alternative gaseous fuels. In this arrangement, the mixture of air and gaseous fuel (CNG-hydrogen) will be admitted into the combustion chamber along with the air intake and compressed while the diesel is used as a pilot fuel to produce auto ignition inside the combustion chamber. This dual-fuel system can be operated both as $100 \%$ diesel or a mixture of CNG-hydrogen with diesel [51-53].

Mixture homogeneity is one of the most important factors that affect combustion efficiency, engine performance, and the reduction of gas emissions. The combustion process inside the engine is directly related to the homogeneity of the mixture inside the engine that affects the emissions [54,55]. Several investigations have reported that $\mathrm{HC}$ emissions are created as a result of the incomplete combustion inside the engine. The majority of PMs are produced by incomplete combustions of HCs in the lube oil and fuel along with their combustion with heterogeneous air-fuel mixtures. Complete combustion in internal combustion engine will reduce the emitted $\mathrm{CO}$ and NO. Thus, enhancing the combustion process and reducing emissions are directly related to enhancing the homogeneity of the mixture (air-fuel) inside the engine [54,56-58].

One problem of gaseous mixers is their incapacity to prepare a homogeneous mixture of air and fuel at a specific air-fuel ratio (AFR) prior to entering the engine. This issue leads to high brake-specific fuel consumption and high exhaust emissions [59-61]. Many studies have indicated that the mixture formation of gaseous fuel with air is more critical than that of liquid fuel with air because of its lower density and fuel penetration. Although gaseous fuels can easily mix with air because of their high diffusivity property, the time for mixing may be insufficient, particularly at high engine speeds, thus resulting in a poor mixture [54].

\section{The New Mixer Design}

In the present work, a new air- $\mathrm{H}_{2}-\mathrm{CNG}$ mixer suitable for mixing air with $\mathrm{CNG}$ and $\mathrm{HCNG}$ under different modes (dual fuel engine: Diesel-CNG and tri-fuel engine: Diesel- $\mathrm{H}_{2}-\mathrm{CNG}$ ) was designed and developed. In addition to that this the new mixer will provide homogeneous mixtures of gaseous fuel and air according to engine speeds with a high uniformity index. The new air fuel mixer with a movable mechanical mechanism was designed to control the air-fuel ratios inside the mixer through an ECU which controls the valve movement according to the engine speed. The new mixer consists of two main types of parts, as shown in Figures 1 and 2:

- Stationary parts: these include the air inlet, fuel inlet, mixing outlet, fuel manifold, bolts, nuts, covers, groove pin, and the main body of mixer and seals.

- Moveable mechanical parts: these consist of the valve, bevel gears, large nut, shafts, and the dual direction stepper motor.

During car movement, the speed, torque, and power of the engine are directly proportional to the quantities of air and fuel required by the engine. In other words, the amount of air that enters the engine changes according to the engine speed, torque, and power requirements. The ECU connected to the engine gives signals to the stepper motor. Then, the stepper motor rotates, which in turn then rotates the shaft, small bevel gear, large bevel gear, and nut until the power screw. The rotary movement of the nut changes to a linear movement for the power screw-valve unit. The valve can move in two directions depending on the direction of the rotary movement for the stepper motor. Thus, the valve can reduce or increase the area of the fuel inlet connected directly to the valve. Such 
movement results in a decrease or increase of the amount of fuel depending on the amount of air that enters the engine and the engine speed in turn so the required air fuel ratio is achieved.

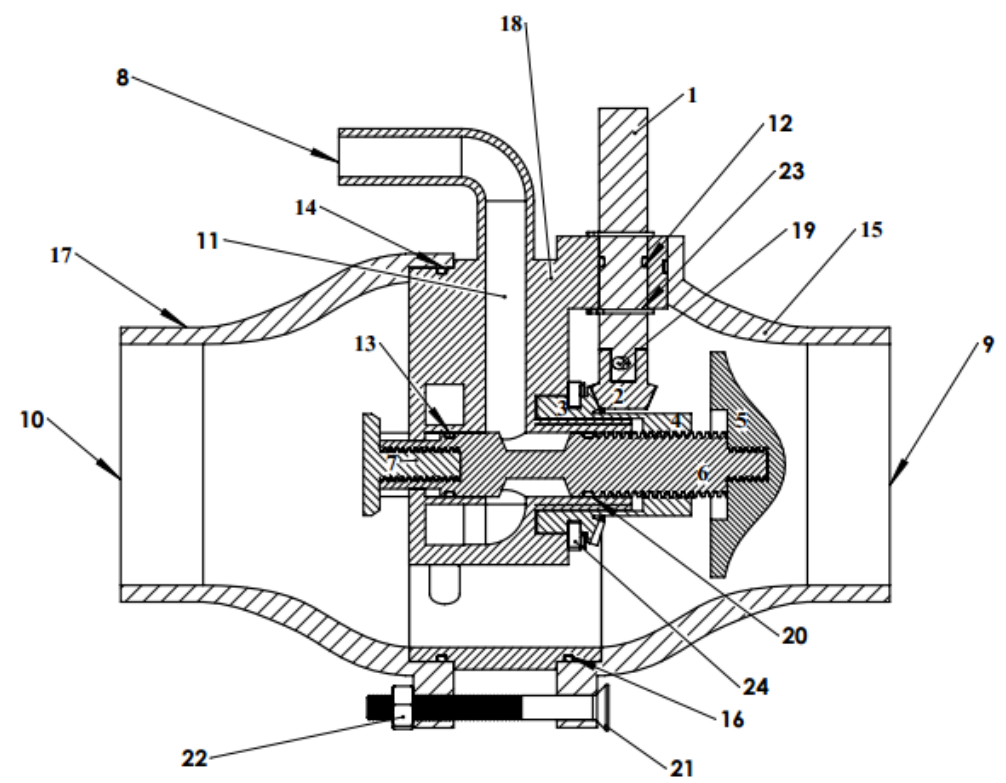

Figure 1. New mixer parts:(1) Shaft connect with stepper motor; (2) Small bevel gear; (3) Large bevel gear; (4)Large nut; (5) Valve head; (6) Valve body; (7) Valve screw; (8) Fuel inlet; (9) Air inlet; (10) Mixing outlet; (11) Fuel manifold; ( 12,13,14,16 and 20) O- rings; (15 and 17) Covers; (18) Main body; (19) Groove pin; (21) Bolt; (22) Nut; (23 and 24) Retaining rings (circlip).

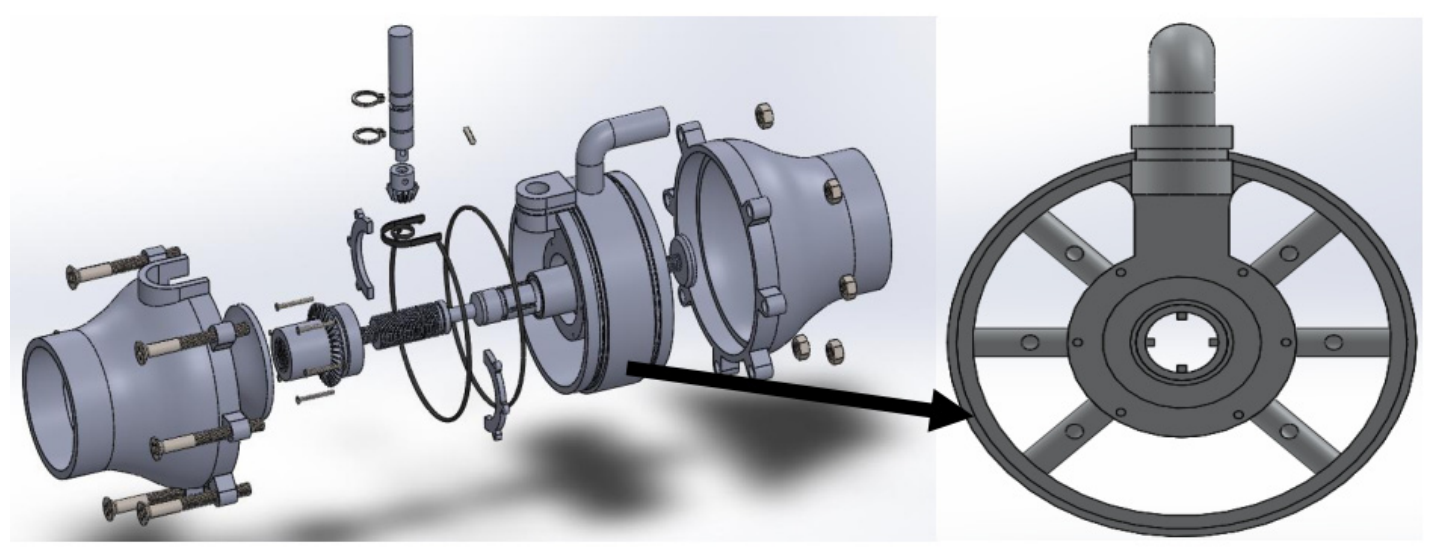

Figure 2. Three-dimensional view of the new mixer.

\section{Optimization the Homogeneity of the Mixture inside the New Mixer}

To provide homogeneous mixtures with high uniformity index for gaseous fuel with air (CNG-hydrogen-air) inside the new mixer, fifteen different mixer models were created to investigate the effects of the diameters, locations (XL1, XL2, XL3 and XL4), and numbers of holes inside the new mixer on the homogeneity and distribution of the mixture (see Table 1 and Figure 3). The flow directions of the fuel through the holes for models 1-6 and models 9-11 were the same as those of the airflow direction, while the flow direction of the fuel through the holes for models 7 to 8 and models 12 to 15 was opposite to the airflow direction (Table 1). The new mixer models without the movable mechanical mechanism were drawn using the ANSYS workbench software. The variations in the modified models are presented in Table 1. In this part of study, the blend of CNG and hydrogen would 
enter the mixer from the fuel inlet in HCNG-diesel tri fuel engine while only CNG will enter to mixer from the fuel inlet in (CNG-diesel dual fuel engine).

Table 1. The models and cases that used to study the homogeneity and distribution of the mixture inside the mixer.

\begin{tabular}{|c|c|c|c|c|c|c|c|c|}
\hline $\begin{array}{c}\text { XL1 } \\
(\mathrm{mm})\end{array}$ & $\begin{array}{c}\mathrm{XL2} \\
(\mathrm{mm})\end{array}$ & $\begin{array}{l}\text { XL3 } \\
(\mathrm{mm})\end{array}$ & $\begin{array}{c}\text { XL4 } \\
(\mathrm{mm})\end{array}$ & $\begin{array}{l}\text { Angle of } \\
\text { Hole }\end{array}$ & $\begin{array}{l}\text { Number } \\
\text { of Holes }\end{array}$ & $\begin{array}{l}\text { Diameter of } \\
\text { Holes (d) mm }\end{array}$ & Position of Holes & Model \\
\hline 0 & 0 & 13.64 & 0 & 0 & 7 & 3.866 & In the center of mixer & Model 1 \\
\hline 32.804 & 0 & 0 & 0 & 0 & 7 & 3.8273 & In edges of mixer $(\mathrm{E})$ & Model 2 \\
\hline 37.51 & 0 & 13.64 & 0 & 0 & 14 & 2.730728 & $\begin{array}{l}\text { In the center and } \\
\text { edges of mixer }\end{array}$ & Model 3 \\
\hline 27.28 & 42.28 & 0 & 0 & 0 & 14 & 2.730728 & In the edges of mixer & Model 4 \\
\hline 37.51 & 0 & 0 & 23.87 & 0 & 6 & 4.176377 & In edges of mixer $(\mathrm{E})$ & Model 5 \\
\hline 27.28 & 42.28 & 0 & 23.87 & 0 & 12 & 2.95306 & In edges of mixer (E) & Model 6 \\
\hline 29.441 & 0 & 0 & 0 & 180 & 6 & 4.176377 & In edges of mixer $(\mathrm{E})$ & Model 7 \\
\hline 27.28 & 42.28 & 0 & 0 & 180 & 12 & 2.95306 & In edges of mixer $(\mathrm{E})$ & Model 8 \\
\hline 37.51 & 42.28 & 13.64 & 0 & 0 & 21 & 2.23014 & $\begin{array}{l}\text { In the center and } \\
\text { edges of mixer }\end{array}$ & Model 9 \\
\hline 25.91 & 0 & 0 & 15.40 & 0 & 6 & 4.176377 & In edges of mixer $(\mathrm{E})$ & Model 10 \\
\hline 34.1 & 42.28 & 0 & 15.40 & 0 & 12 & 2.95306 & In edges of mixer $(\mathrm{E})$ & Model 11 \\
\hline 37.51 & 0 & 0 & 15.40 & 180 & 6 & 4.176377 & In edges of mixer (E) & Model 12 \\
\hline 37.51 & 42.28 & 0 & 15.40 & 180 & 12 & 2.95306 & In edges of mixer (E) & Model 13 \\
\hline 37.51 & 0 & 0 & 23.87 & 180 & 6 & 4.176377 & In edges of mixer (E) & Model 14 \\
\hline 25.916 & 42.28 & 0 & 23.87 & 180 & 12 & 2.95306 & In edges of mixer (E) & Model 15 \\
\hline
\end{tabular}

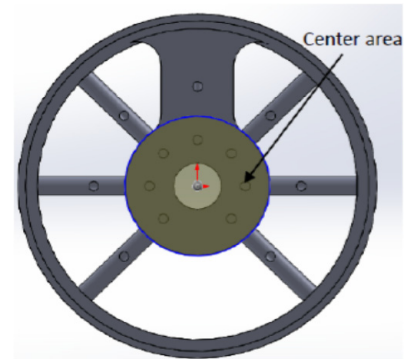

(a)

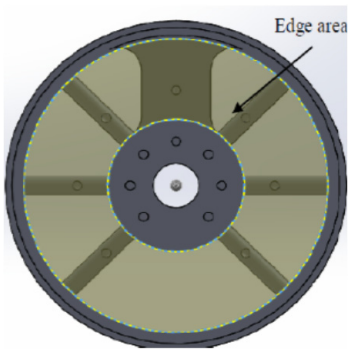

(b)

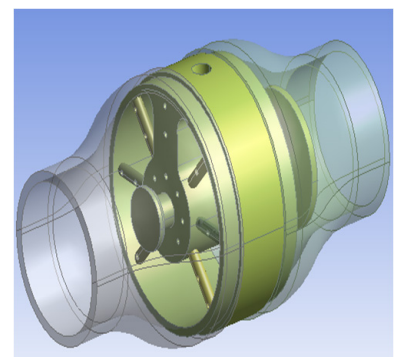

(c)
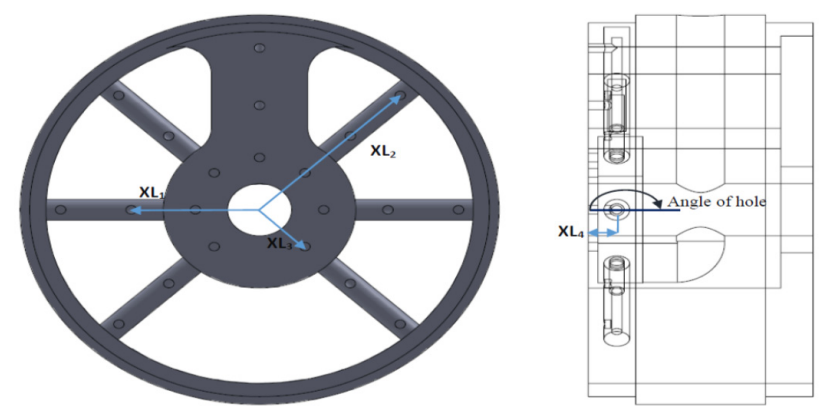

(d)

Figure 3. Parameters of main controller body of mixer: (a) Central area; (b) Edge area; (c) Isometric view; (d) The distances between the holes and the mixer centers.

\section{Computational Fluid Dynamics Analysis (CFD)}

In this work, ANSYS workbench CFD was used to generate a multi-block structured mesh for the geometries, and ANSYS Fluent was used to conduct a single-phase multi-species flow simulation. Reynolds Averaged Navier Stokes equations (RANS) are the governing equations of CFD. The 3D steady RANS equations are solved by using a finite-volume, pressure-based, and fully implicit code. This is a universal code used for modeling a wide range of industrial problems involving fluid flow, heat transfer (including radiation), turbulence, mixing of chemical species, multi-step chemistry, two-phase flows, moving-rotating bodies, and other complex physics problems [52,62-64]. Although, the RANS model has been used for modeling a wide range of industrial problems, fundamental limitations exist. The RANS model is inherently incapable of capturing unsteady effects, like intermittent separation 
and eddy generation and transport, and generally has difficulty modeling turbulence in areas of strong separation [65].

\subsection{Drawing the Mixer}

The design modeler software in the ANSYS workbench was utilized to draw new mixer models without the movable mechanical mechanism as shown in Figure 4. The geometries of new mixer models included volumes, surfaces, edges, and vertices.

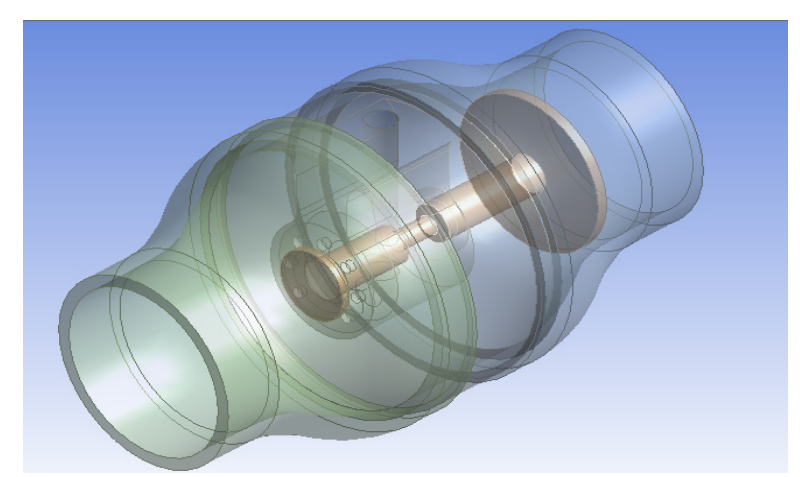

(a)

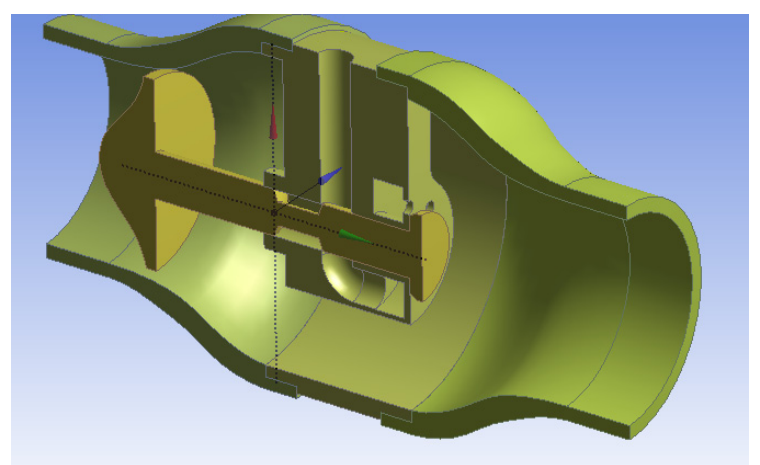

(b)

Figure 4. The geometry of the mixer after drawing using the ANSYS workbench software: (a) Isometric view of mixer; and (b) Section view of mixer.

\subsection{Model of Turbulence}

The standard k- $\varepsilon$ model/high Reynolds number with isothermal heat transfer condition at $300 \mathrm{~K}$ was selected for this work. According to the literature, this model is identified as the most consistent and reliable one to produce results in a timely manner. The standard wall function selected for this work was the near wall treatment, which produced considerable valid results in the case of a high-Reynolds number flow (turbulent) $[55,63,66]$. Moreover, there are some limitations of using the k-epsilon turbulence model as shown below:

- Generally, performs poorly for flows with larger pressure gradient, strong separation, high swirling component and large streamline curvature.

- Inaccurate prediction of the spreading rate of round jets.

- The $\varepsilon$ equation contains a term which cannot be calculated at the wall. Therefore, wall functions must be used.

\subsection{Numerical Diffusion}

A dominant source of error in multi-dimensional situations is numerical diffusion (false diffusion). The term false diffusion is used because the diffusion is not a real phenomenon, yet its effect on a flow calculation is analogous to that of increasing the real diffusion coefficient. Numerical diffusion can occur when the flow situation is dominated by convection, i.e., the real diffusion is small. In addition, it can be also occur when the cells are not parallel to the flow, which will lead to transport of species due to discretization. All practical numerical schemes for solving fluid flow contain a finite amount of numerical diffusion. This is because numerical diffusion arises from truncation errors that are a consequence of representing the fluid flow equations in discrete form. The numerical diffusion can be minimized in two different ways, as shown below [67,68]:

(1) If a higher order discretization scheme is used in ANSYS Fluent, such as QUICK or second order upwind, the effect of numerical diffusion will be reduced. In this study, second order upwind discretization for momentum, turbulence equations, energy equations, and all equations for gases (species equation) was used [69]. 
(2) The amount of numerical diffusion is inversely related to the resolution of the mesh, therefore, one way of minimizing the numerical diffusion is to refine the mesh [67].

\subsection{Grid Generation and Grid Independence Test}

New mixer models were meshed using ANSYS workbench 16. The tetrahedrons method, patch conforming, inflation, and curvature were used to mesh the new mixer models. The tetrahedrons method divided the mixer into tetrahedral elements. The numbers of nodes and elements affected the accuracy of the results and the required time for the simulation.

A grid-independence test (GIT) for the mesh was conducted on Model 1 to select the suitable numbers of nodes and elements that provide highly accurate results and save simulation time, which would then be applied on new mixer models. Six different cases of meshing were selected to conduct the GIT on the Model 1 (see Table 2 and Figure 5). The GIT for the six cases was achieved by comparing the results of mass fraction of CNG along a line in the $Z$-axis direction and a line in $y$-axis inside the existing mixer (Figures 6-8). Moreover, the GIT for the six cases was done by comparing the results of mass fraction and uniformity index of CNG at outlet of the existing mixer (Figures 9 and 10). Meshing case 3 was selected depending on the grid-dependence test because it provide highly accurate results and save simulation time.

Table 2. Number of nodes and elements used in the simulation for grid dependence test for Model 1.

\begin{tabular}{ccc}
\hline Cases & Elements & Nodes \\
\hline Case 1 & 672,690 & 153,813 \\
Case 2 & 707,664 & 167,052 \\
Case 3 & 813,774 & 179,236 \\
Case 4 & 932,208 & 201,231 \\
Case 5 & 1054,756 & 223,744 \\
Case 6 & 1227,136 & 265,304 \\
\hline
\end{tabular}
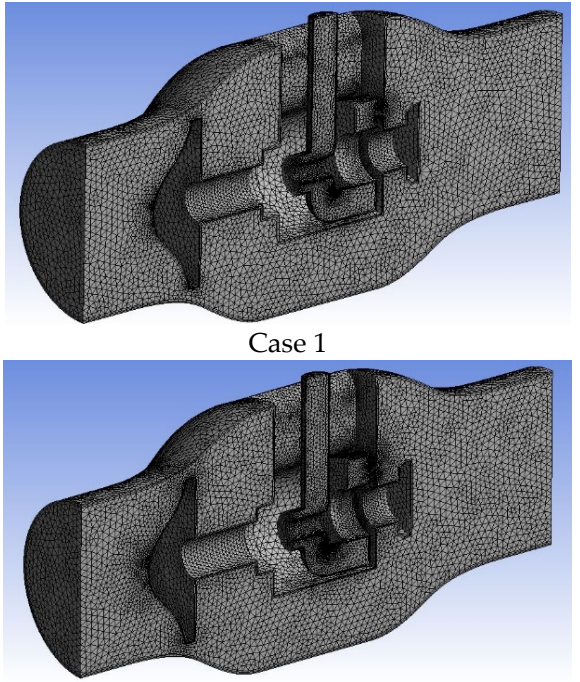

Case 3

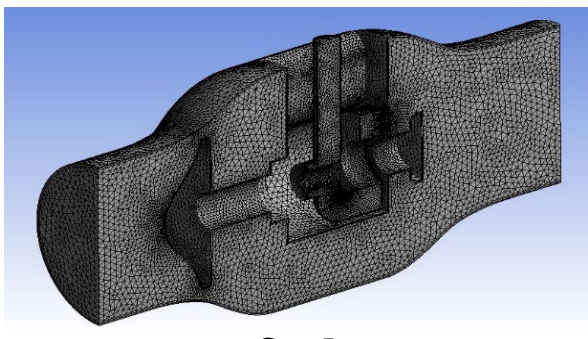

Case 5

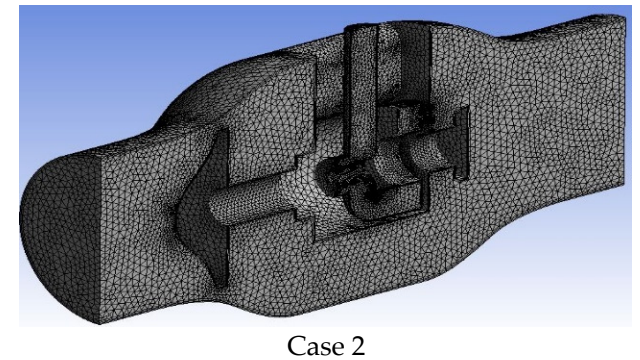

Case 2

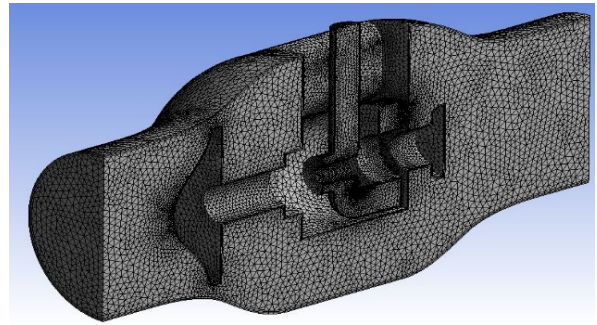

Case 4

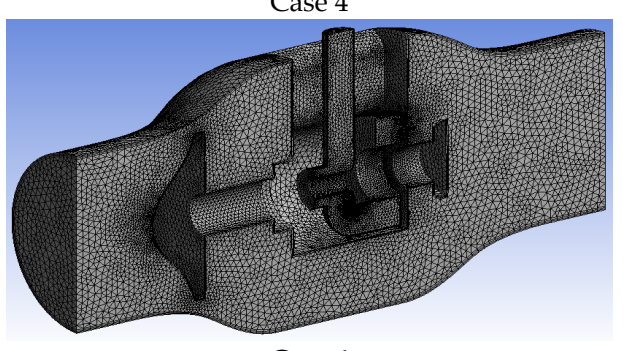

Case 6

Figure 5. Cases of meshing that used in the Grid-independence test. 


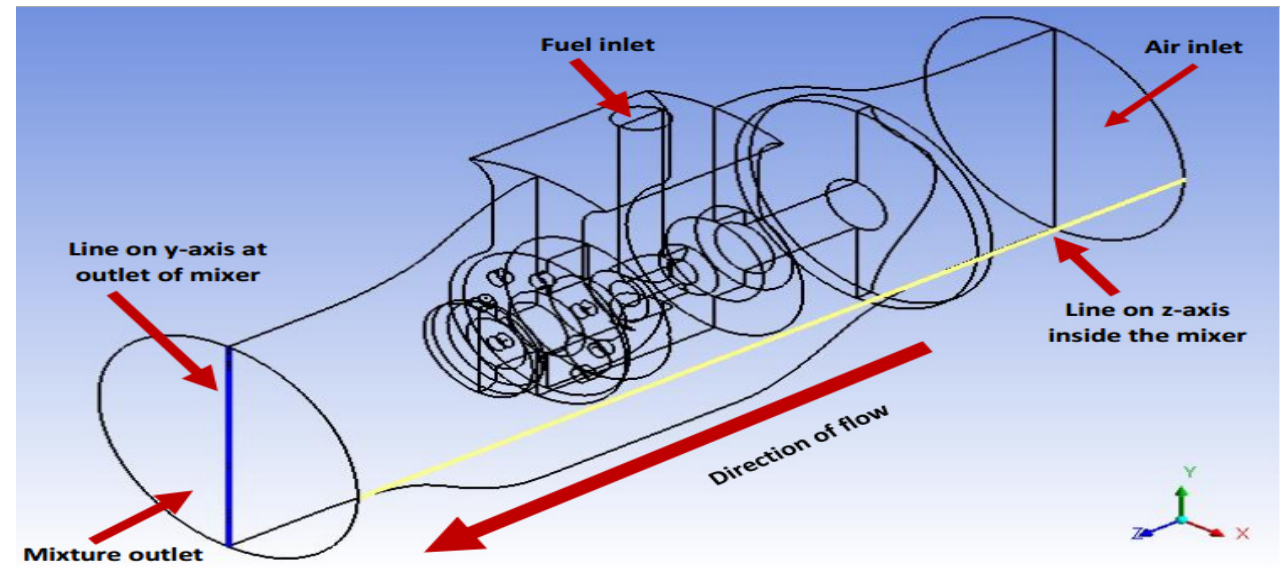

Figure 6. A line in Z-axis direction inside the model 1 which will applied on the four case of meshing.

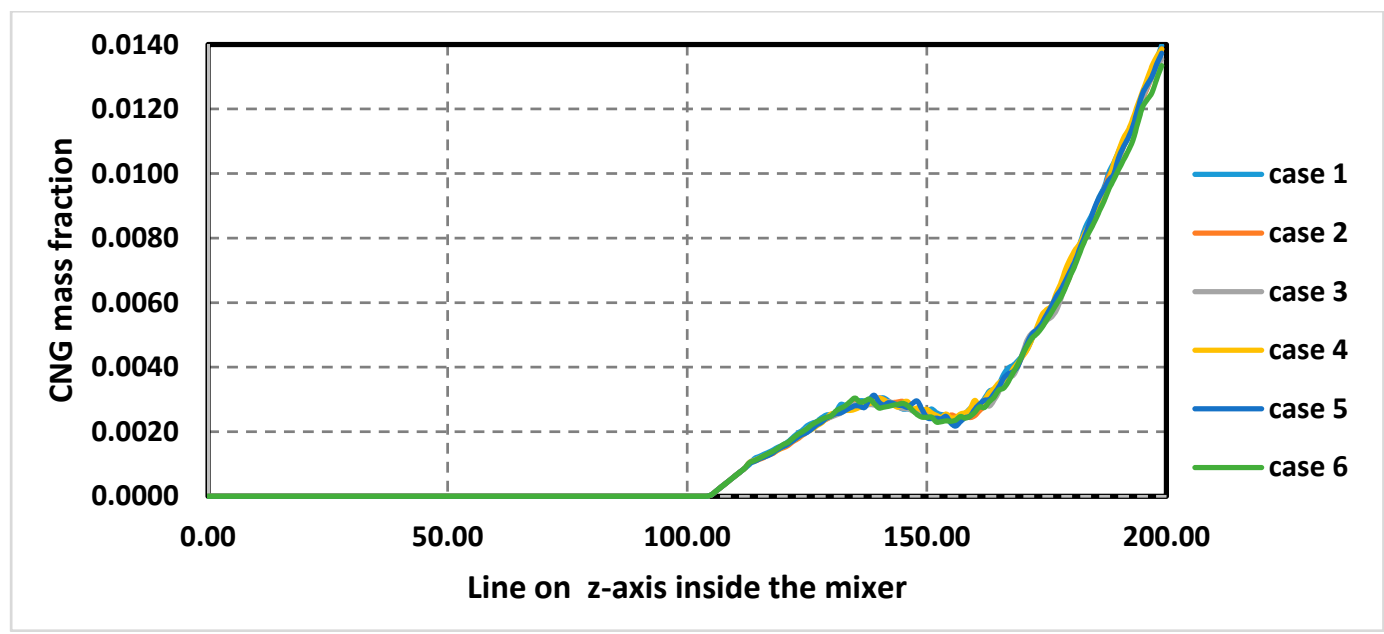

Figure 7. CNG mass fraction on line along $x$-axis inside mixer outlet (model1), grid independence test results.

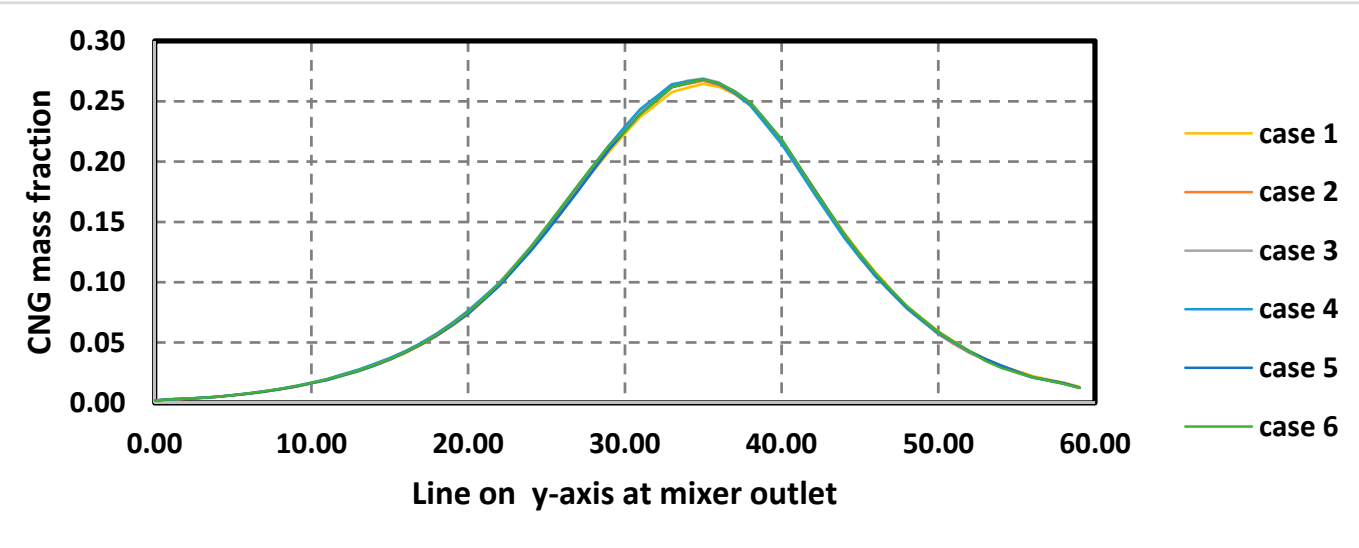

Figure 8. CNG mass fraction on line in y-axis at mixer outlet (model 1), grid independence test results. 


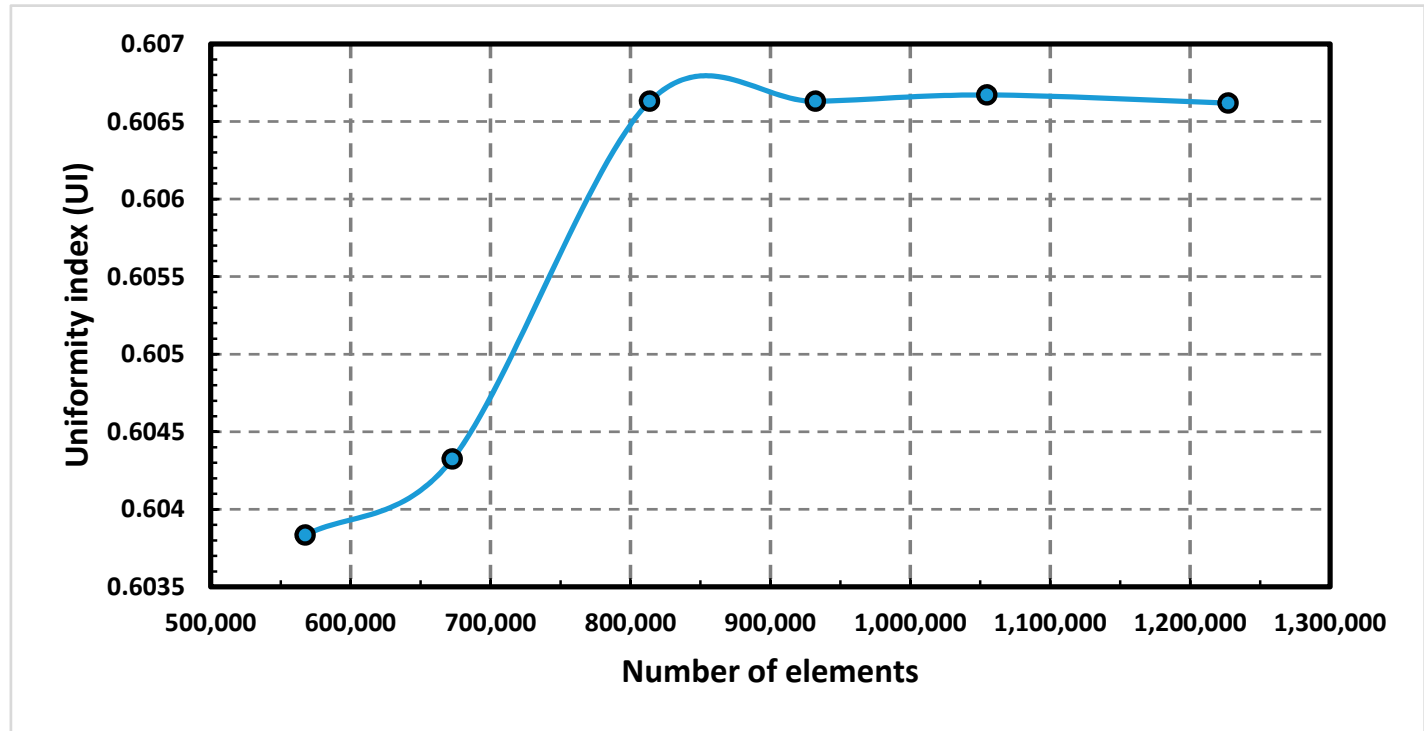

Figure 9. Uniformity index at mixer outlet (model 1), grid independence test results.

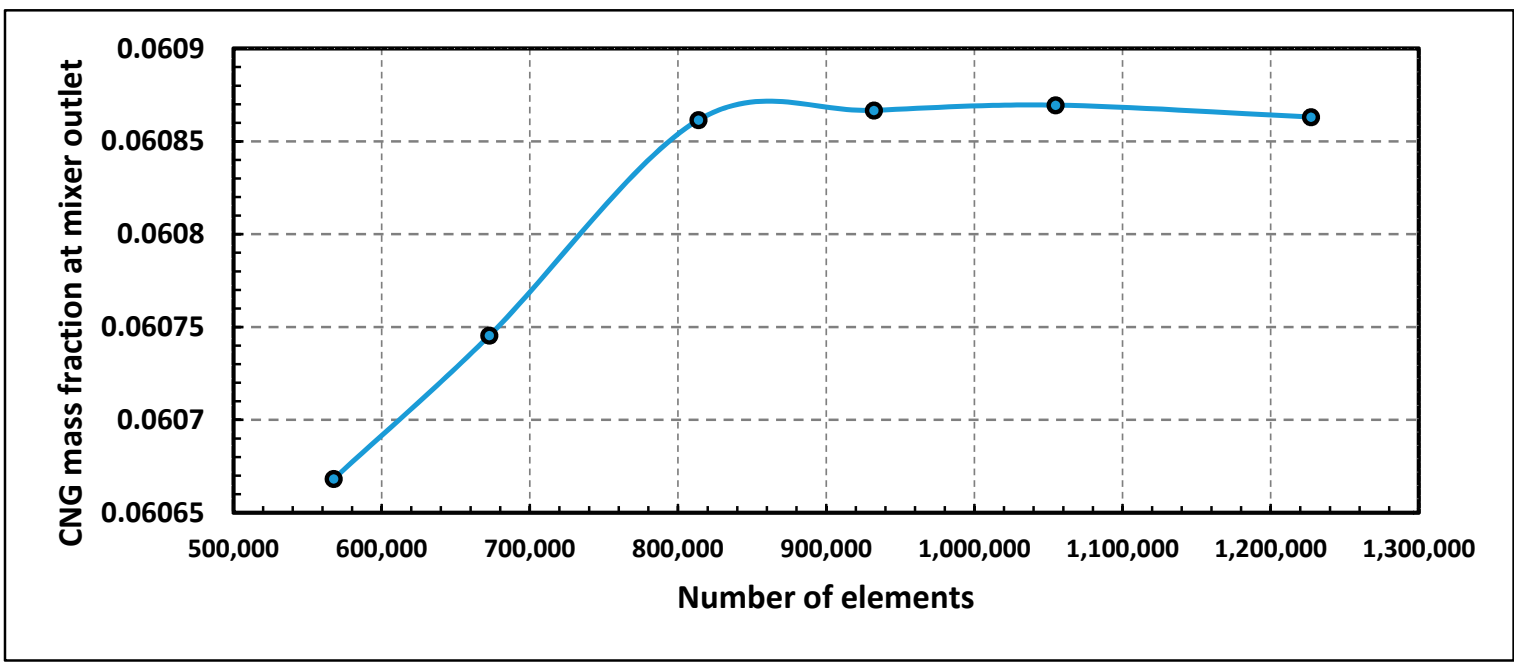

Figure 10. CNG mass fraction at mixer outlet (model 1), grid dependence test results.

\subsection{Evaluation of Flow Uniformity}

The homogeneity and distribution of the air and fuel mixture across the mixer outlet significantly affect the enhancement of engine performance, the reduction of exhaust emissions, and the durability of the mixer. The quantitative parameter flow uniformity index (UI) has been widely used in the automotive industry to evaluate the mixing distribution inside the mixer, catalyst inlet, and engine. UI can be expressed as follows [70-72]:

$$
U I=1-\frac{1}{2} \frac{\sum_{i=1}^{n}\left|w_{i}-w_{\text {mean }}\right| A_{i}}{A w_{\text {mean }}}
$$

where $w_{i}$ : the local mass fraction; $A_{i}$ : the local area; $A$ : the cross area where $U I$ is evaluated, and the mean mass fraction was computed as:

$$
w_{\text {mean }}=\frac{1}{A} \sum_{i=1}^{n} w_{i} A_{i}
$$


where $i$ is the local grid cell and $n$ is the number of grid cells within the cross-section plane. According to the above definition, $U I$ ranges between 0 and 1 . When $(U I)=1$, the fuel distribution is totally homogeneous; when (UI) approaches zero, the fuel is completely unmixed with other gases.

\subsection{Boundary Condition for the New Mixer Models}

The following two boundary conditions were used to simulate the flow inside the new mixer models (Figure 11) [55]:

(1) The air inlet boundary-The mass flow rate was considered constant at the air inlet. The values of mass fraction were (1) for air and (0) for gaseous fuel. Air consists of oxygen $(0.23 \%)$ and Nitrogen $(0.77 \%)$ by mass fractions (Figure 11$)$.

(2) The fuel inlet boundary-The mass flow rate was considered constant at the fuel inlet. The values of mass fraction for air, methane, and hydrogen are respectively listed below (Table 3) (Figure 11).

The outlet boundary-The outlet boundary-target mass flow rate is used at the mixer outlet. With this option the Bernoulli equation is used to adjust the pressure at every iteration on pressure outline zone in order to meet the desired mass flow rate (Figure 11).

Table 3. Mass fraction settings in ANSYS fluent software according to type of fuel and mixing ratio.

\begin{tabular}{cccc}
\hline The Case & Mass Fraction of Air & Mass Fraction for Hydrogen & Mass Fraction for CNG \\
\hline CNG-Air & 0 & 0 & 1 \\
HCNG-Air (H70\%-CNG 30\%) & 0 & 0.052300514 & 0.947699486 \\
\hline
\end{tabular}

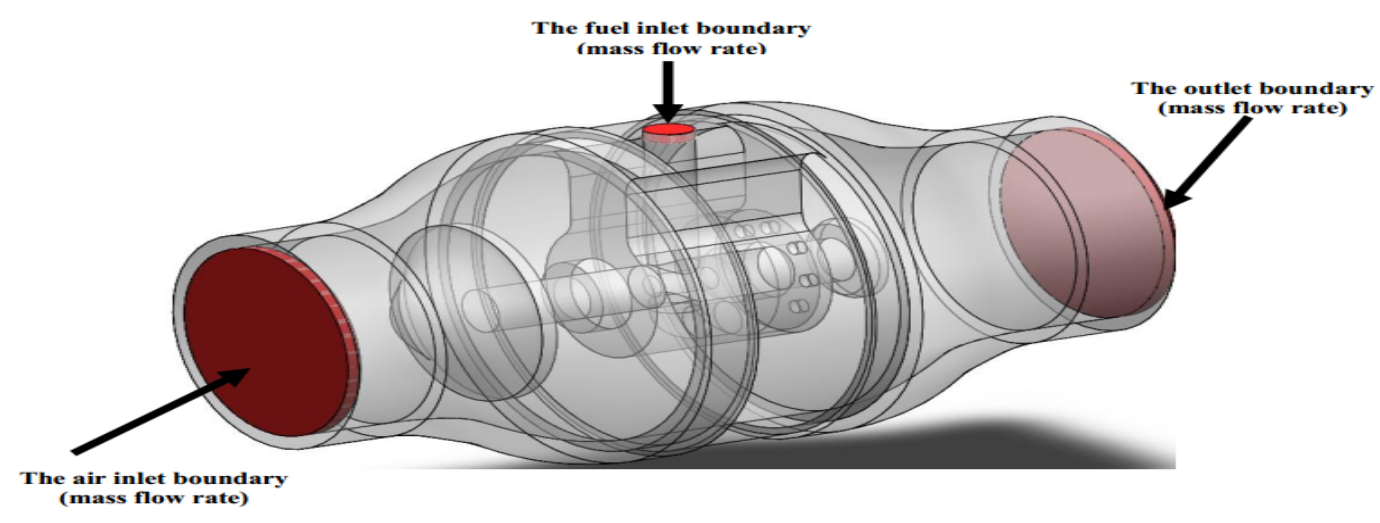

Figure 11. The boundary conditions for three-dimensional mixer.

\subsection{Air-Gaseous Fuel Ratio}

The air-fuel ratio is among the most important factors in designing the mixer. The stoichiometric air-fuel ratio refers to the minimum amount of air required for completing fuel combustion. In this study, the substitution ratio of gaseous fuel (blend of CNG and hydrogen or CNG) by energy with diesel energy in the dual-fuel (CNG-Diesel) and tri-fuel (H-CNG-Diesel) engines was set to $50 \%$, as follows $[33,53,73]$ :

$$
\text { substitution ratio }=\frac{\dot{m}_{\text {gaseous fuel }} \times L H V_{\text {gaseous fuel }}}{\dot{m}_{\text {Diesel }} \times L H V_{\text {Diesel }}+\dot{m}_{\text {gaseous fuel }} \times L H V_{\text {gaseous fuel }}}
$$

where $\dot{m}_{D}$ and $\dot{m}_{\text {gaseous fuel }}$ are the mass flow rates of diesel and gaseous fuels in $\mathrm{kg} / \mathrm{h}$, respectively. $L H V_{\text {gaseous fuel }}$ and $L H V_{D}$ represent the lower heating values of diesel and gaseous fuels in $\mathrm{MJ} / \mathrm{kg}$, respectively (Table 4). The AFR for the gaseous fuel (CNG-hydrogen) inside the engine and the mixer is shown in Table 5. 
Table 4. Diesel and Gaseous fuel properties [44,47].

\begin{tabular}{ccccccc}
\hline & Methane & H30-M70 & H50-M50 & H70-M30 & Hydrogen & Diesel \\
\hline Density $\left(\mathrm{Kg} / \mathrm{m}^{3}\right)$ & 0.65 & 0.48 & 0.37 & 0.25 & $8.36 \times 10^{-2}$ & $833-881$ \\
LHV $(\mathrm{MJ} / \mathrm{Kg})$ & 50.02 & 53.57 & 57.79 & 65.81 & 119.93 & 42.8 \\
Stoichiometric AFR $(\mathrm{Kg} / \mathrm{Kg})$ & 17.25 & 22.39 & 25.82 & 29.25 & 34.39 & 14.5 \\
Flammability limits (Vol \% in air) & $5-15$ & - & - & - & $4-75$ & $0.7-5$ \\
Auto ignition temperature & 813 & - & - & - & 858 & $477-533$ \\
\hline
\end{tabular}

Table 5. Air-fuel ratio for CNG-Hydrogen-Diesel with air.

\begin{tabular}{cccccc}
\hline $\begin{array}{l}\text { Type of } \\
\text { Mixing }\end{array}$ & $\begin{array}{c}\text { Air/Gaseous Fuel } \\
\text { inside the Mixer }\end{array}$ & $\begin{array}{c}\text { Air/Gaseous Fuel } \\
\text { inside the Engine }\end{array}$ & $\begin{array}{c}\text { Gaseous fuels } \\
\text { Substitution Ratio } \\
\text { by Energy with } \\
\text { Diesel Fuel }\end{array}$ & $\begin{array}{c}\text { Content CNG in } \\
\text { Gaseous Fuel that } \\
\text { Enters inside the } \\
\text { Mixer }\end{array}$ & $\begin{array}{c}\text { Content Hydrogen } \\
\text { in Gaseous Fuel } \\
\text { that Enters inside } \\
\text { the Mixer }\end{array}$ \\
\hline CNG-Air & 34.15 & 15.76 & $50 \%$ & 100 & 30 \\
HCNG-Air & 51.31 & 20.34 & $50 \%$ & NA* \\
70
\end{tabular}

\section{Results}

The homogeneity and distribution of the mixture (air-gaseous fuel) in the new mixer models (15 models) were checked and tested using the ANSYS software. Two AFRs were used to examine the performance of the mixers in terms of gaseous fuel-air mixture homogeneity (AFRHCNG $=51.31$ and AFRCNG = 34.15). The mass fraction distribution of gaseous fuel (HCNG or CNG) inside the mixers (color contours of mass fraction for gaseous fuel and volume rendering of gaseous fuel) and the UI at the outlet of the mixers were calculated using ANSYS software to evaluate the mixture homogeneity. The simulation results on the homogeneity and distribution of the mixture were analyzed as shown below.

\subsection{Uniformity Index of Gaseous Fuel inside the New Mixer Models}

UI was used to estimate the air-gaseous fuel mixture homogeneity at the outlet of the mixers (15 models). Table 6 shows the UI values for gaseous fuel at the mixer outlet for the new mixer models. The lowest UI values for gaseous fuel are 0.646 (AFRHCNG = 51.31) and 0.606 (AFRCNG = 34.15), which are obtained using Model 1. By contrast, the highest UI values of 0.939 at AFRHCNG $=51.31$ and 0.937 at AFRCNG $=34.15$ for gaseous fuel are obtained using Model 7.

Table 6. The value of uniformity index according to the simulation results for new mixer models.

\begin{tabular}{ccc}
\hline The Models & The UI Value Under Air-HCNG Ratio 51.315 & The UI Value Under Air-CNG Ratio 34.15 \\
\hline Model 1 & 0.646 & 0.606 \\
Model 2 & 0.859715 & 0.824727 \\
Model 3 & 0.751899 & 0.798 \\
Model 4 & 0.8912 & 0.8855 \\
Model 5 & 0.889061 & 0.892846 \\
Model 6 & 0.911697 & 0.909 \\
Model 7 & 0.939 & 0.937 \\
Model 8 & 0.912487 & 0.911825 \\
Model 9 & 0.796095 & 0.809 \\
Model 10 & 0.883703 & 0.834379 \\
Model 11 & 0.884979 & 0.875965 \\
Model 12 & 0.91904 & 0.923 \\
Model 13 & 0.919954 & 0.920503 \\
Model 14 & 0.9199822 & 0.922 \\
Model 15 & 0.9185988 & 0.921 \\
\hline
\end{tabular}

According to Table 6, Model 1 produces the lowest UI value for the mixture of gaseous fuel and air in comparison with the other cases of the new mixer models. This result is due to the fact that the holes are located at the center of the mixer and away from the direction of the airflow and that the main body of the mixer contains a block in the middle. These reasons prevent gaseous fuel from 
mixing directly with air. Furthermore, the distance between the holes and the mixer outlet is very close so that the time for mixing air with gaseous fuel is insufficient.

As indicated in Table 6, the worst UI values in comparison with the other models are obtained in models 1, 3 and 9. This result is obtained because some or all holes are concentrated at the center of the mixer and away from the direction of the airflow; hence, the fuel is concentrated at the center of the mixer, whereas the area that is near the edge of the mixer outlet contains a low concentration of gaseous fuels.

Moreover, when the direction of the holes is same to that of the airflow (angle 0), some or all holes is distribution in center of mixer when the variable value XL4 is constant, it was noticed that increasing the number of holes leads to increase the diffusivity of the mixture and values of uniformity Index. This is due to the fact that increasing the number of holes leads to increase the propagation of gas inside the mixer.

As exhibited in Table 6, the UI value of gaseous fuel in Model 1 (seven holes at the mixer center with XL4 $=24 \mathrm{~mm}$ ) is lower than that in Model 3 (seven holes at the mixer edges and seven holes at the center of the mixer with XL4 $=24 \mathrm{~mm}$ ) under AFRHCNG $=51.31$ and AFRCNG $=34.15$, whereas the UI value of gaseous fuel in Model 9 (14 holes at the mixer edges and seven holes at the center of the mixer with XL4 $=24 \mathrm{~mm}$ ) is higher than that in Model 3 (seven holes at the mixer edges and seven holes at the center of the mixer with XL4 =24mm) under AFRHCNG $=51.31$ and AFRCNG $=34.15$.

These tables also show that increasing the number of holes leads to increased mixture homogeneity and UI values when the direction of the holes is the same as that of the airflow (angle 0), the holes are located at the mixer edges, and when the variable value XL4 is constant. This result is due to the fact that increasing the number of holes leads to increased gas diffusion on the largest possible area inside the mixer. As indicated in Table 6, the UI value of gaseous fuel in Model 2 (seven holes at the mixer edges with XL4 = 24 mm) is lower than that in Model 4 (14 holes at the mixer edges with $\mathrm{XL}=24 \mathrm{~mm}$ ) under AFRHCNG $=51.31$ and $\mathrm{AFRCNG}=34.15$, whereas the UI value of gaseous fuel in Model 6 (12 holes at the mixer edges with $\mathrm{XL}=24 \mathrm{~mm}$ ) is higher than that in Model 5 (six holes at the mixer edges with $\mathrm{XL}=24 \mathrm{~mm}$ ) under AFRHCNG $=51.31$ and $\mathrm{AFRCNG}=34.15$.

As shown in Table 6, increasing the distance between the holes inside the mixer and the mixer outlet leads to increased mixture homogeneity and UI values when the direction of the holes is the same as that of the airflow (angle 0), the holes are located at the mixer edges, and when the number of holes is constant. This result is due to the fact that increasing the distance between the holes and the outlet mixer prolongs the mixing time between air and gaseous fuel, thereby improving mixture homogeneity. As demonstrated in Table 6, the UI value of gaseous fuel in Model 10 (six holes at the mixer edges with XL4 $=24 \mathrm{~mm}$ ) is lower than that in Model 5 (six holes at the mixer edges with $\mathrm{XL} 4=34 \mathrm{~mm}$ ) under AFRHCNG $=51.31$ and AFRCNG $=34.15$, whereas the UI value of gaseous fuel in Model 6 (14 holes at the mixer edges with XL4 = 24 mm) is higher than that in Model 11 (six holes at the mixer edges with XL4 =34 mm) under AFRHCNG $=51.31$ and AFRCNG $=34.15$.

As per Table 6, all the models that have holes with the same direction as the airflow did not achieve the required mixing (UI) for air and gas. This result is due to the fact that the flow inside the models that have holes with the same direction as the airflow is close to streamline flow without low vortices inside the mixer. This condition prevents the complete mixing of air with gaseous fuel. Moreover, the UI range for models $1-6$ and 9-11 under AFRHCNG $=51.31$ and AFRCNG $=34.15$ is between 0.606 and 0.911697 .

The simulation results reveal that the best UI values are obtained in models $7-8$ and $12-15$, where the UI values under AFRHCNG = 51.31and AFRCNG = 34.15 range between 0.9124 and 0.944 . This result is due to that the opposite direction of the holes with the airflow allows the generation of highly turbulent flow with vortices inside the mixer and the mixture of air with gaseous fuel for the longest possible time (Table 6) [54]. Furthermore, increasing the number of holes inside the mixer does not affect the diffusion of gaseous fuel inside the mixer when the direction of the holes is opposite that of the airflow. Moreover, Model 7 shows more gas spreading in comparison with the other models. 


\subsection{Distribution of Mass Fraction for Gaseous Fuel inside the New Mixer Models}

The mass fraction distribution of gaseous fuel inside the mixers was used to evaluate the homogeneity and uniformity of the gaseous-air mixture inside the mixer. The gaseous fuel concentration at the mixer outlet must be uniform and the concentration gradation in the outlet area of the mixer should be convergent to obtain a homogeneous mixture of air and gaseous fuel. Moreover, less number of color contours at the mixing region indicates better mixing.

Figures 12 and 13 show the volume rendering of mass fraction for the gaseous fuel inside the new mixer models. Simulation results reveal that the maximum mass fraction for the gaseous fuel (HCNG or CNG) is at the inlet and manifold of the fuel up to the holes. A noticeable difference is observed in the distribution of gaseous fuel for the spaces after the valve head to the mixer outlet.

Figures 14 and 15 show velocity streamlines for gaseous fuel (CNG and HCNG) inside the new mixer models. As exhibited in Figures 12-15, the flow at all the models whose holes have the same direction as the airflow is close to streamline flow with low vortices inside the mixer, thereby preventing the complete mixing of air and gaseous fuel. However, the flow at all the models whose holes have the opposite direction from the airflow is turbulent with high vortices. This condition allows the mixing of air with gaseous fuel for the longest possible time, thereby producing good homogeneous mixture.

Figures 16 and 17 show user-defined mass fraction contour for the gaseous fuel (HCNG and CNG) inside the new mixer models. As shown in this Figures, the Model 1 provides a non-uniform distribution for gaseous fuel under AFRHCNG $=51.31$ and $\mathrm{AFRCNG}=34.15$. Furthermore, the concentrations of gaseous fuel in the mixer outlet are spaced so that mostly concentrates of gaseous fuel at the mixer center, which is represented by five colors (red, yellow, green, light green and light blue), whereas the concentrations of gaseous fuel at the mixer edges are low, which is represented by one color (dark blue). This condition leads to poor mixing between air and gaseous fuel. Moreover, the simulation results indicate that the model 1 shows the lowest distribution for gaseous fuel among all cases.

As exhibited in Figures 16 and 17, the worst distribution of gaseous fuel at the mixer outlet is obtained in models 1, 3, and 9 in comparison with the other models under AFRHCNG $=51.31$ and $\mathrm{AFRCNG}=34.15$. This result is obtained because some or all holes are concentrated at the center of the mixer and away from the direction of the airflow so that the fuel is concentrated at the center of the mixer while the area that is near the edge of the mixer outlet has a low concentration of gaseous fuels.

The simulation results reveal that most models that have holes with the same direction as the airflow and are located at the mixer edges provide a more homogenous mixture in comparison with the models that have holes with the same direction as the airflow direction but are located at the center of the mixer (Figures 16 and 17).

Figures 16 and 17 illustrate that all the models that have holes with the same direction as the airflow (models 1 to 6 and 9 to 11) do not produce high mixing ratios for air and gas. This result is due to the fact that the flow inside these models is close to the streamline flow with low vortices, thereby preventing the complete mixing of air and gaseous fuel (CNG and $\mathrm{HCNG}$ ).

In addition, the best homogeneity and the highest propagation rate at the mixer outlet are obtained in models $7,8,12,13,14$, and 15. This result is obtained because the direction of the holes is opposite that of the airflow, thereby allowing the generation of highly turbulent flow and high vortices inside the mixer and the mixing of air with gaseous fuel (CNG and $\mathrm{HCNG}$ ) for the longest possible time. Moreover, Model 7 shows more gas spreading in comparison with the other models (Figures 16 and 17). 


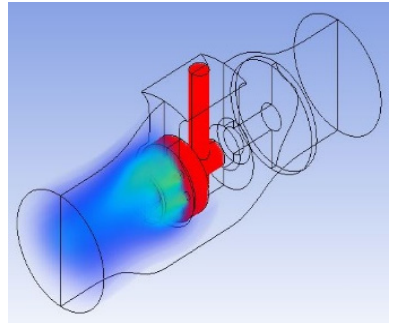

Model 1

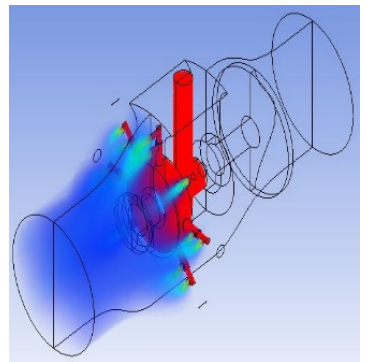

Model 4

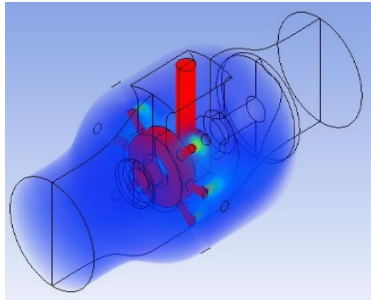

Model 7

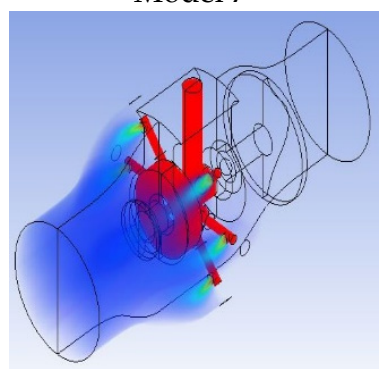

Model 10

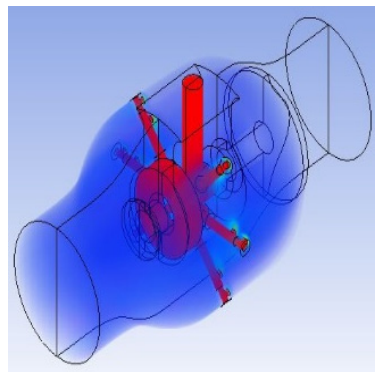

Model 13

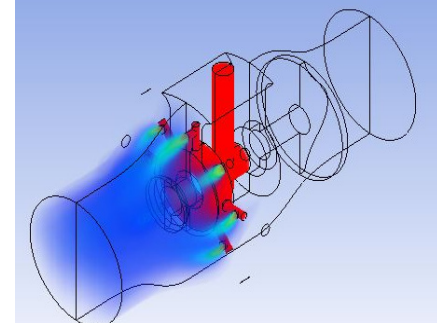

Model 2

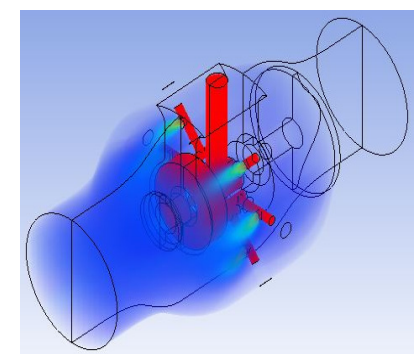

Model 5

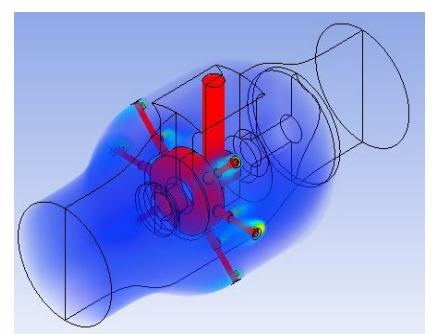

Model 8

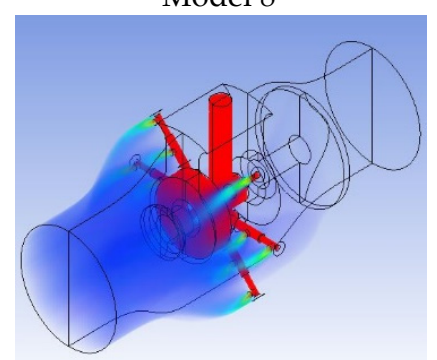

Model 11

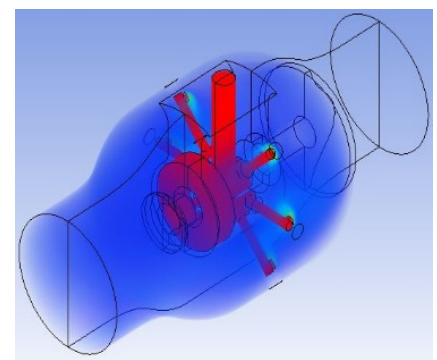

Model 14

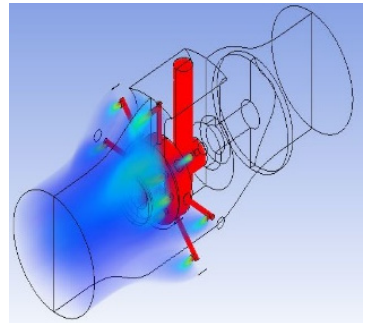

Model 3

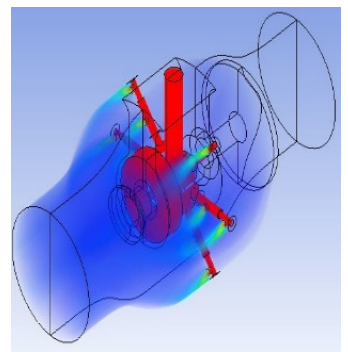

Model 6

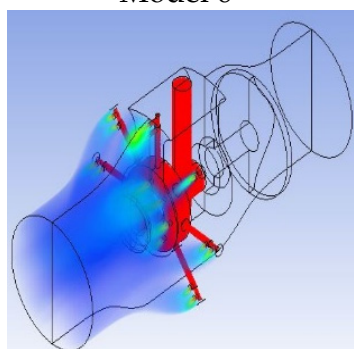

Model 9

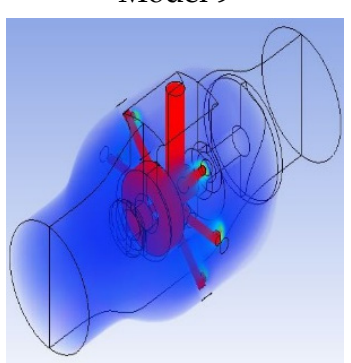

Model 12

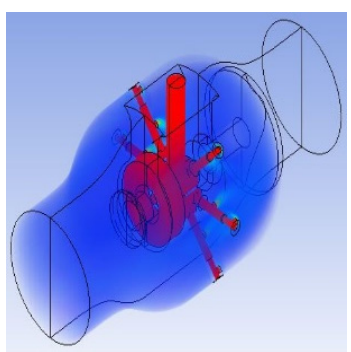

Model 15
Ch4.Mass Fraction Volume Rendering 1

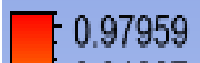

$-0.91837$ $-0.85714$ $-0.79592$ $-0.73469$ $-0.67347$ $-0.61224$ $-0.55102$ $-0.48980$ $-0.42857$ $-0.36735$ 0.30612 $-0.24490$ $-0.18367$

0.12245

0.06122 0.00000

Figure 12. Volume rendering for methane mass fraction of the existing mixer and new mixer models (best case for each model) under air-CNG ratio 34.15 . 


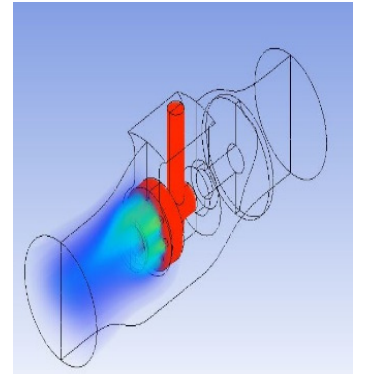

Model 1

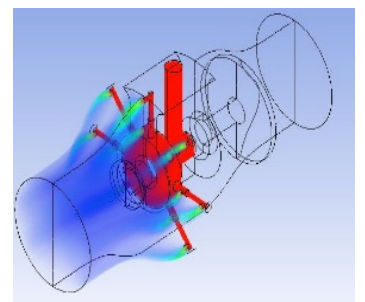

Model 4

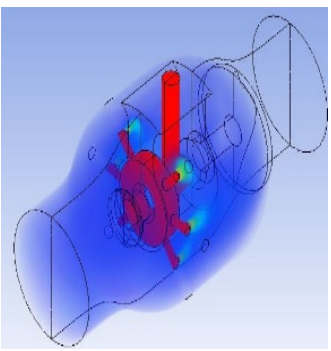

Model 7

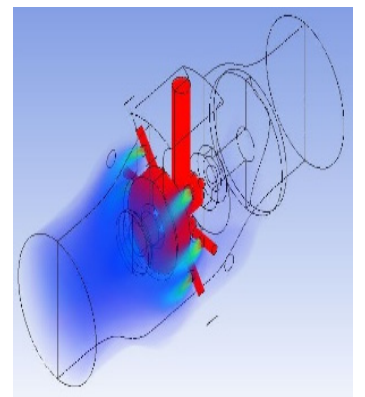

Model 10

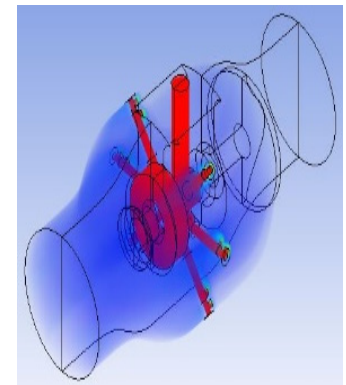

Model 13

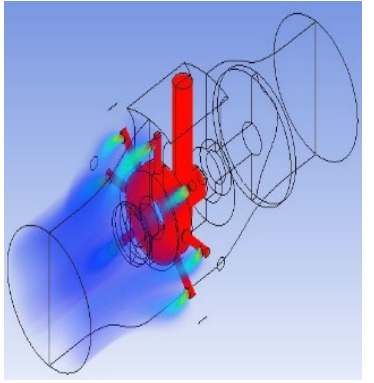

Model 2

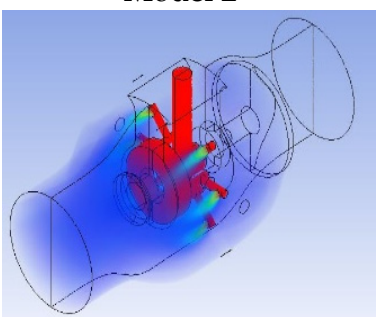

Model 5

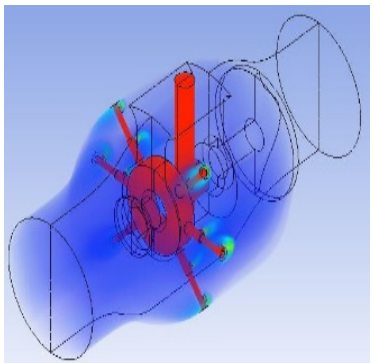

Model 8

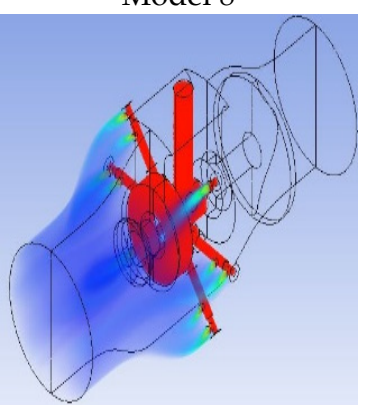

Model 11

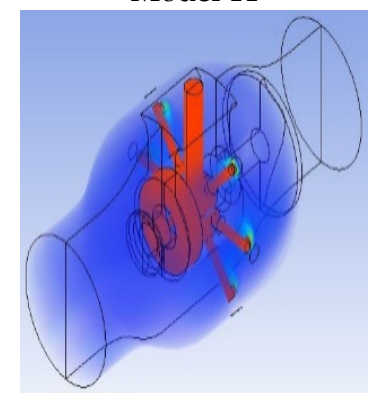

Model 14

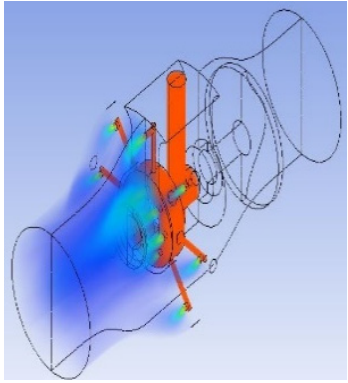

Model 3

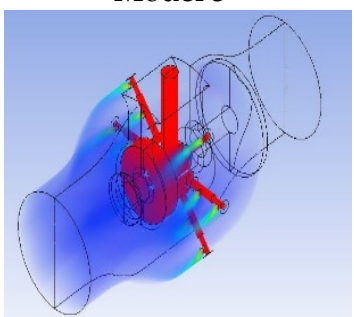

Model 6

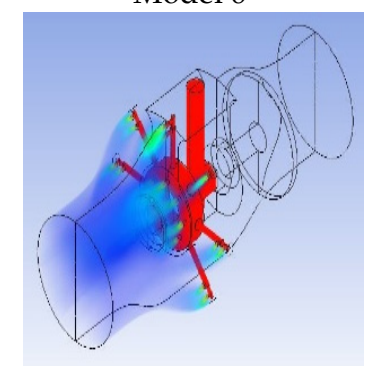

Model 9

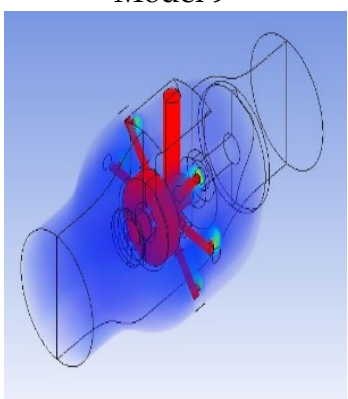

Model 12

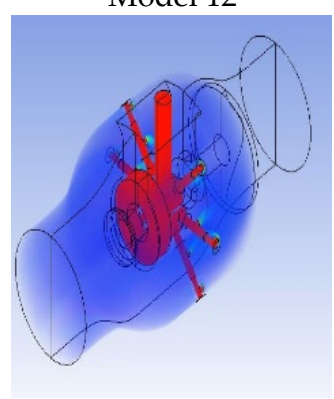

Model 15
H2.Mass Fraction Volume Rendering 1

0.2336

0.2190

$-0.2044$

$-0.1898$

$-0.1752$

$-0.1606$

$-0.1460$

$-0.1314$

0.1168

$-0.1022$

$-0.0876$

$-0.0730$

$-0.0584$

0.0438

0.0292

0.0146

0.0000

Ch4.Mass Fraction Volume Rendering 1

0.7604 $-0.7129$ $-0.6654$

$-0.6178$

$-0.5703$

$-0.5228$

$-0.4753$

$=0.4277$

$-0.3802$

$-0.3327$

$-0.2852$

$-0.2376$

$-0.1901$

$-0.1426$

0.0951

0.0475

0.0000

Figure 13. Volume rendering for methane mass fraction of the existing mixer and new mixer models (best case for each model) under Air-HCNG ratio 51.315. 


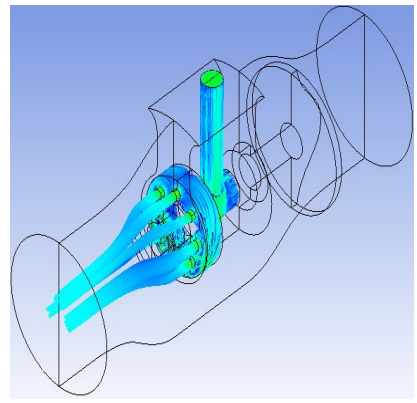

Model 1

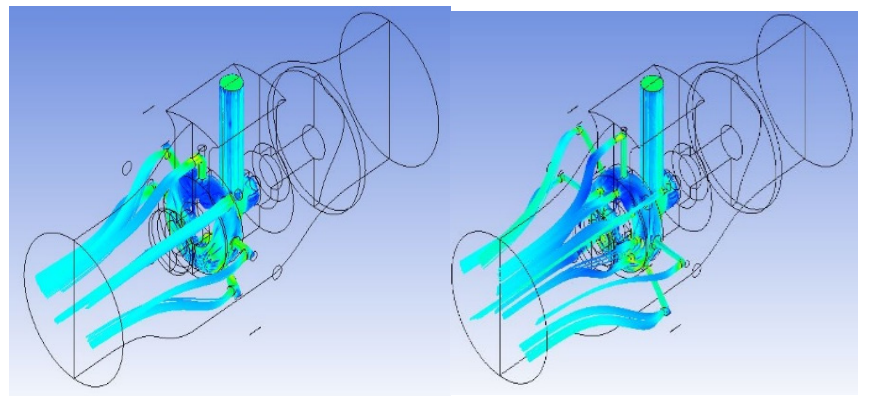

Model 2

Model 3

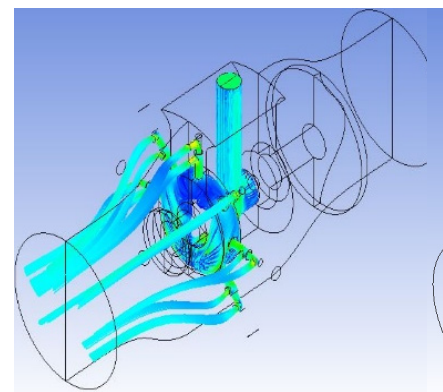

Model 4

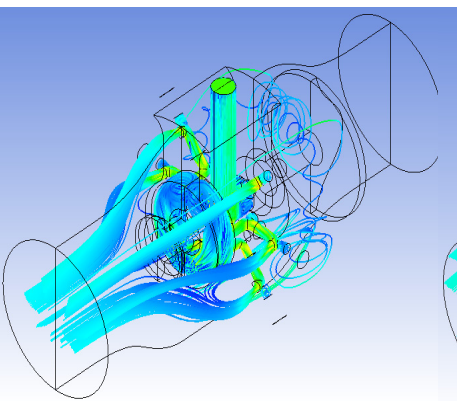

Model 5

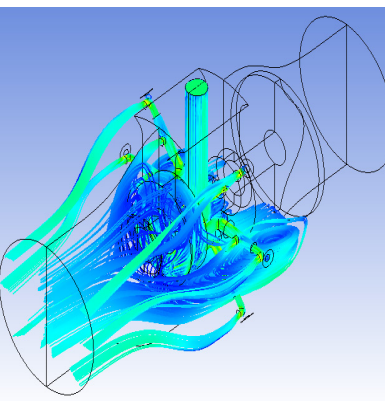

Model 6

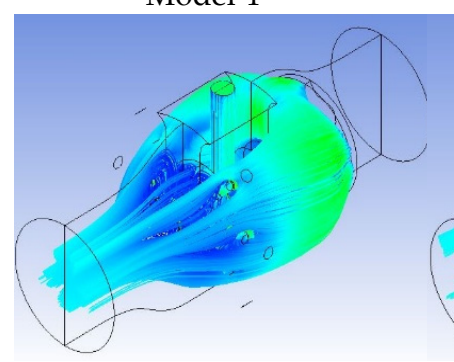

Model 7

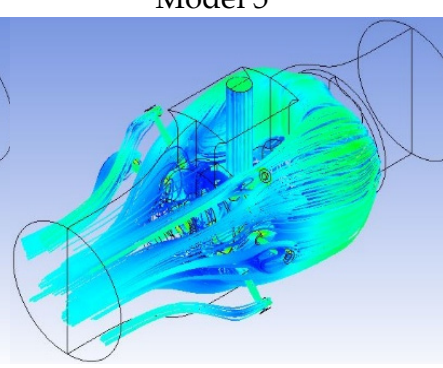

Model 8

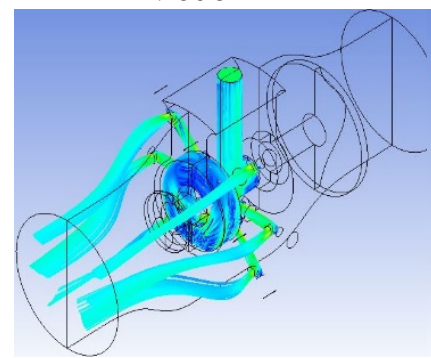

Model 10

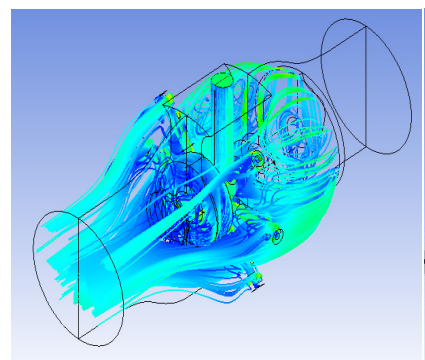

Model 13

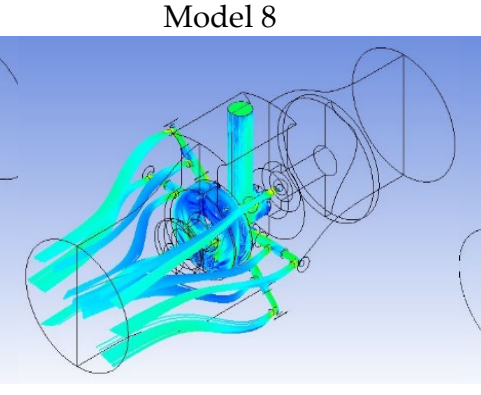

Model 11

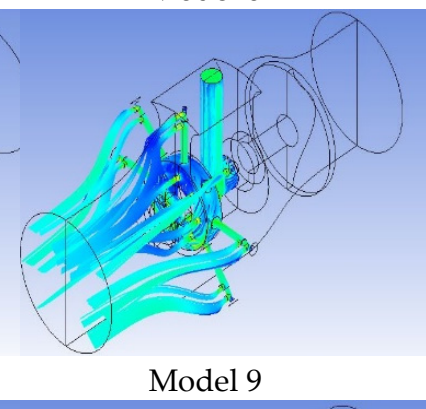

Velocity Volume Rendering 1

137.195

$-129.974$

122.753

$-115.533$

$-108.312$

$-101.091$

93.870

$-86.649$

$-79.429$

$-72.208$

$-64.987$

$-57.766$

$-50.546$

$-43.325$

$-36.104$

$-28.883$

21.662

$-14.442$

7.221

$\left[\mathrm{m} \mathrm{s}^{\wedge}-1\right]$

Figure 14. Velocity streamline (with 1000 points at CNG inlet) for new mixer models under air-CNG ratio 34.15 . 


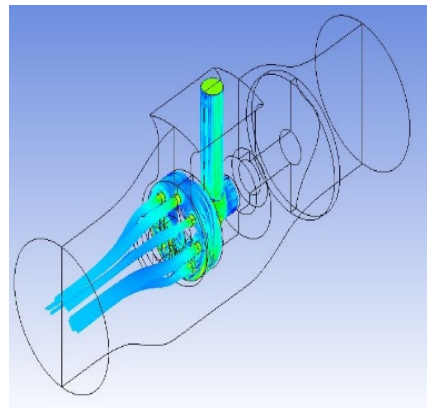

Model 1

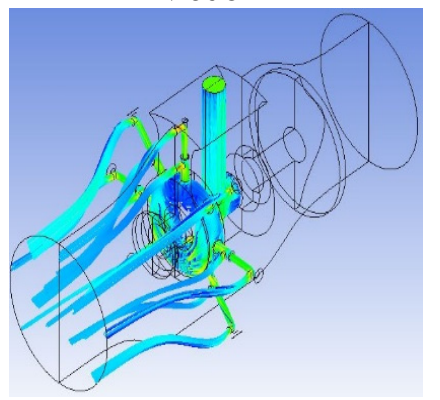

Model 4

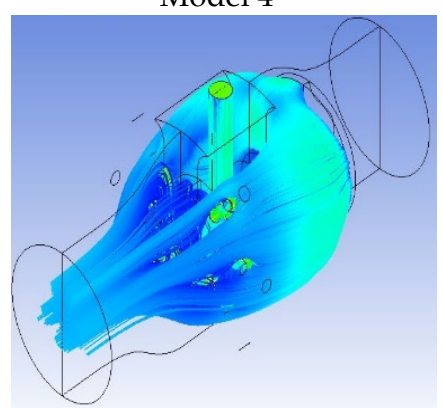

Model 7

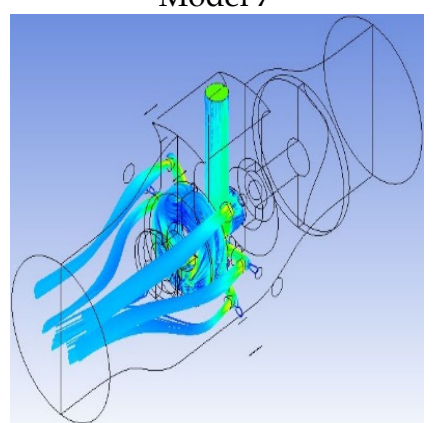

Model 10

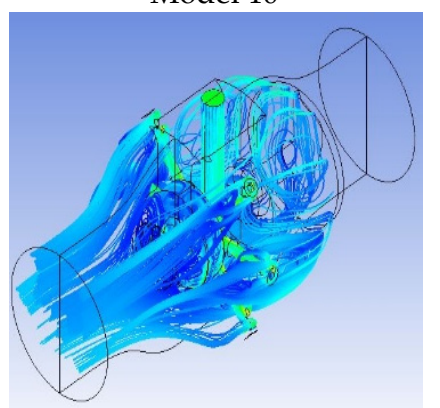

Model 13

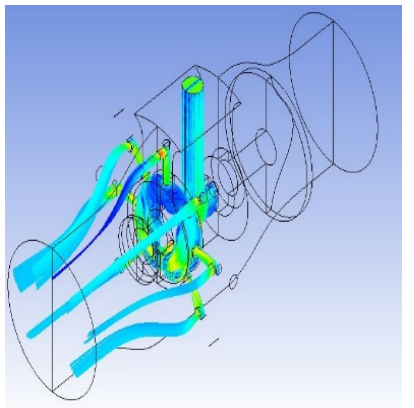

Model 2

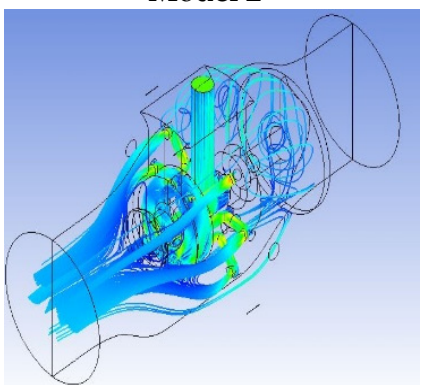

Model 5

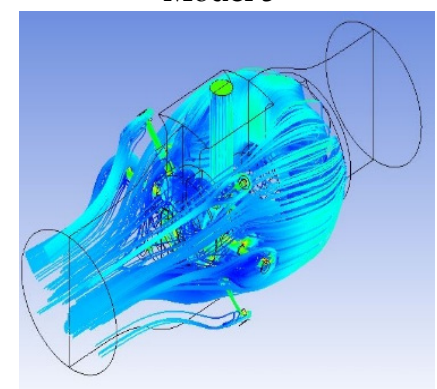

Model 8

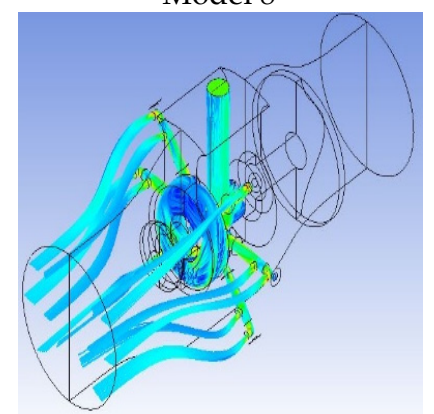

Model 11

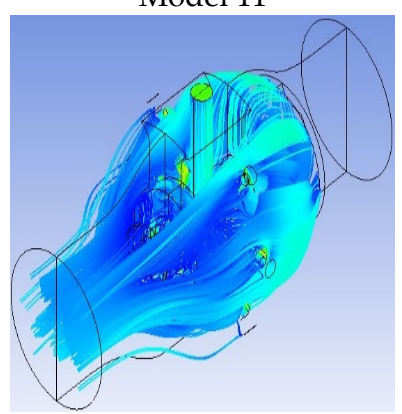

Model 14

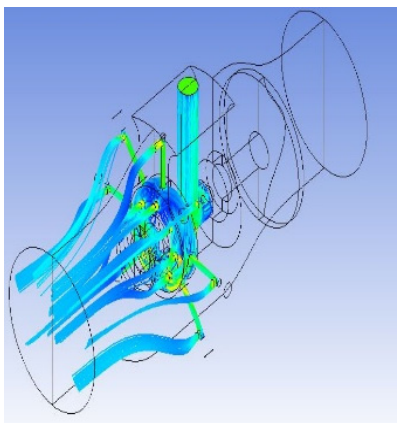

Model 3

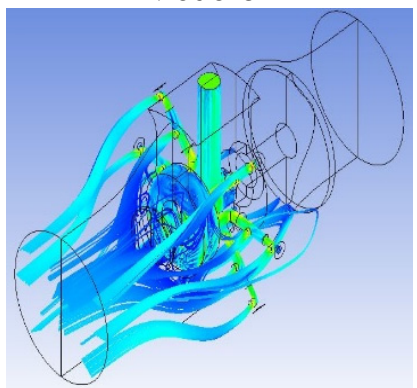

Model 6

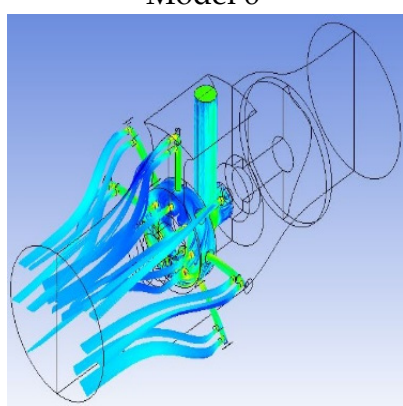

Model 9

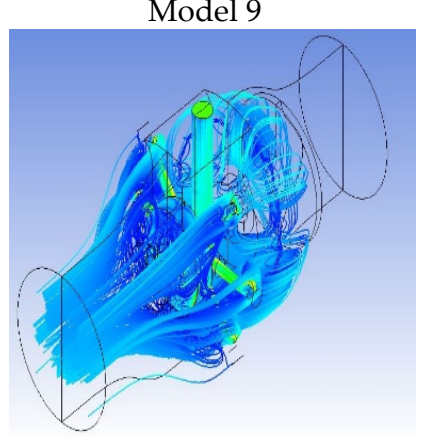

Model 12

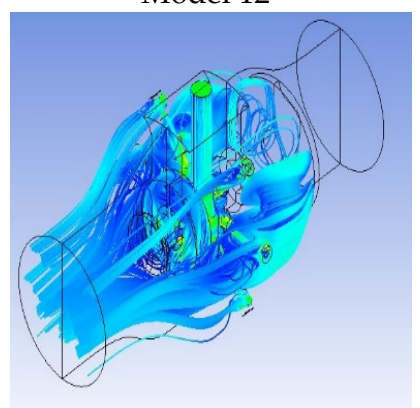

Model 15

Velocity
Volume Rendering
\begin{tabular}{|l|l}
181.750 \\
-170.390 \\
-159.031 \\
-147.672 \\
-136.312 \\
-124.953 \\
-113.593 \\
-102.234 \\
-90.875 \\
-79.515 \\
-68.156 \\
56.797 \\
-45.437 \\
34.078 \\
-22.719 \\
11.359 \\
0.000
\end{tabular}
[m s $\left.\mathrm{s}^{\wedge}-1\right]$

Figure 15. Velocity streamline (with 1000 points at HCNG inlet) for new mixer models under Air-HCNG ratio 51.315 . 


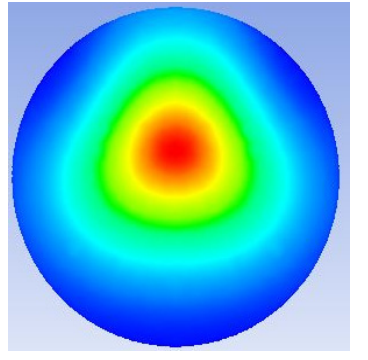

Model 1

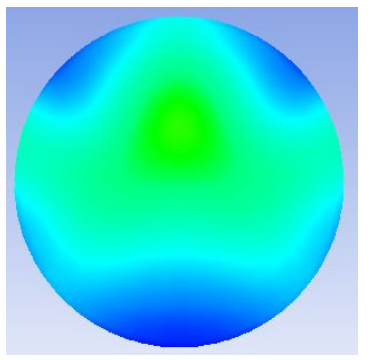

Model 4

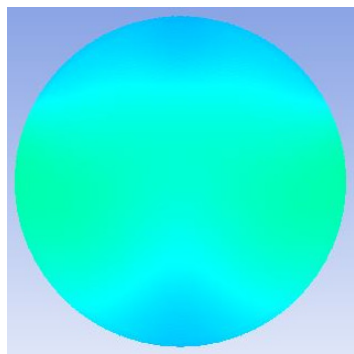

Model 7

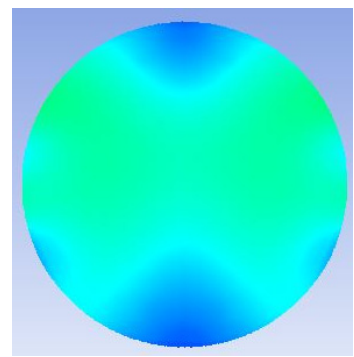

Model 10

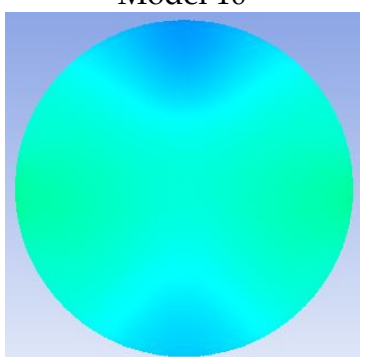

Model 13

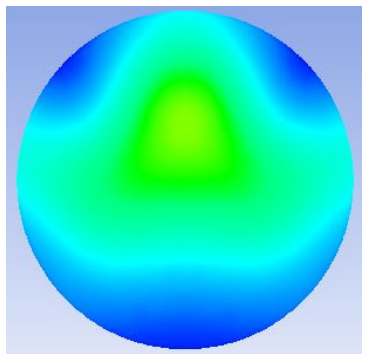

Model 2

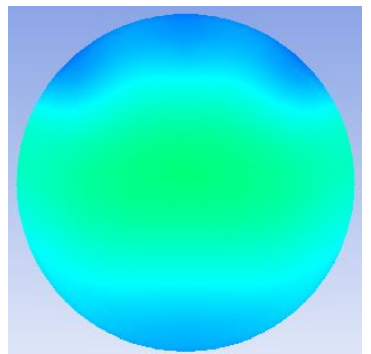

Model 5

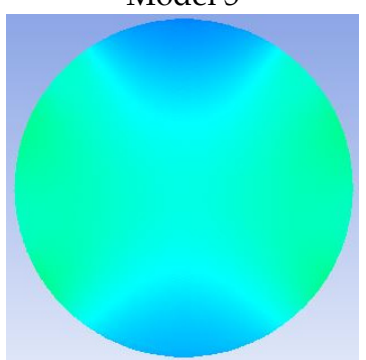

Model 8

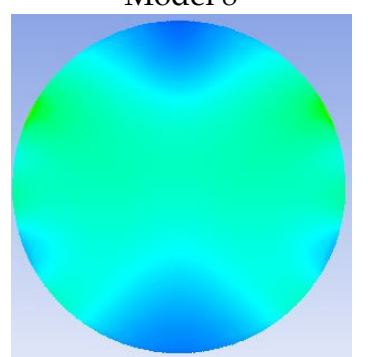

Model 11

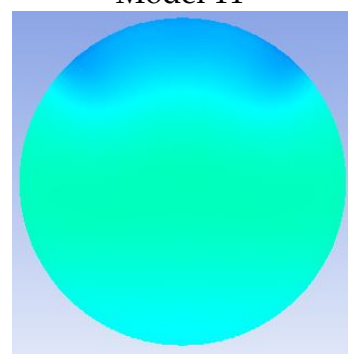

Model 14

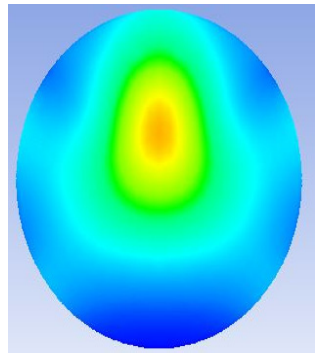

Model 3

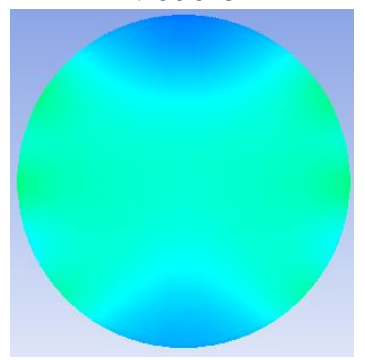

Model 6

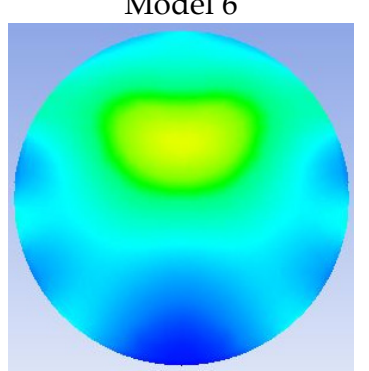

Model 9

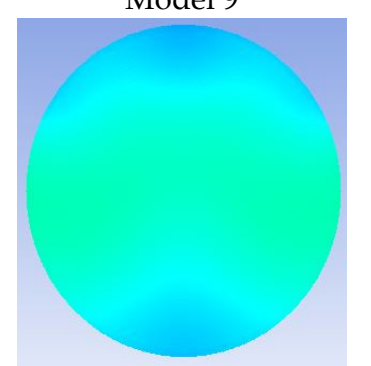

Model 12

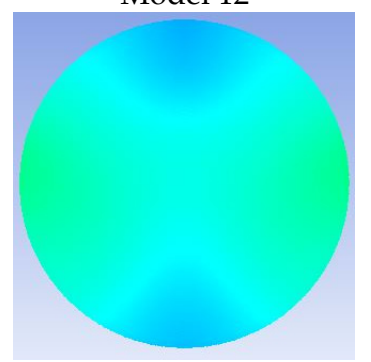

Model 15

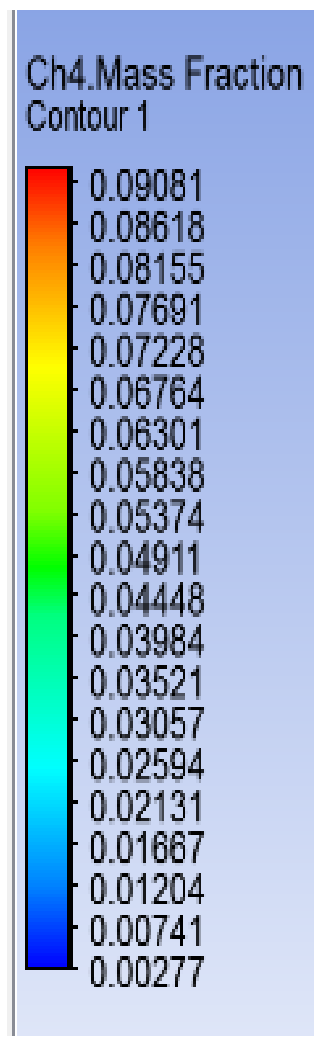

Figure 16. User-defined methane mass fraction contour at outlet of the existing mixer and new mixer models (best case for each model) under air-CNG ratio 34.15. 


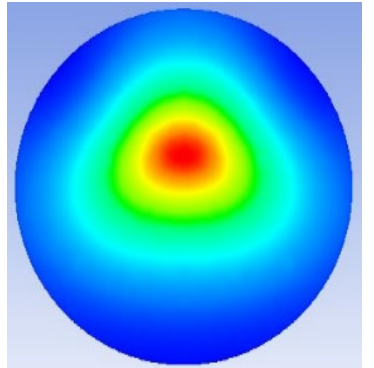

Model 1

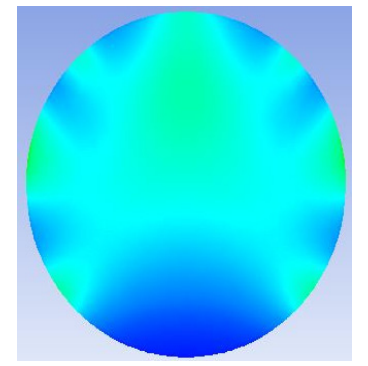

Model 4

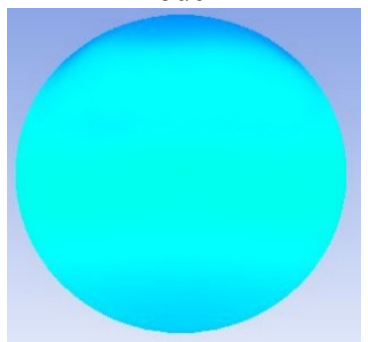

Model 7

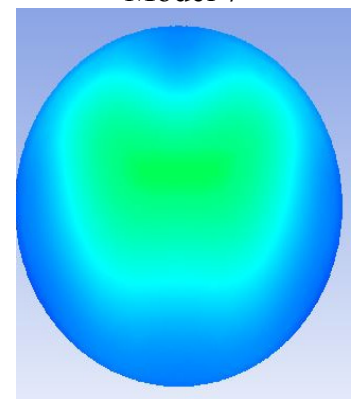

Model 10

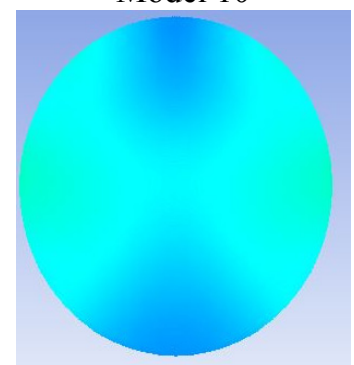

Model 13

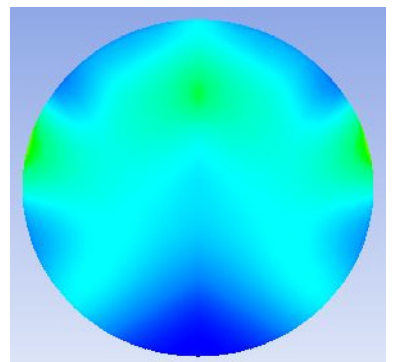

Model 2

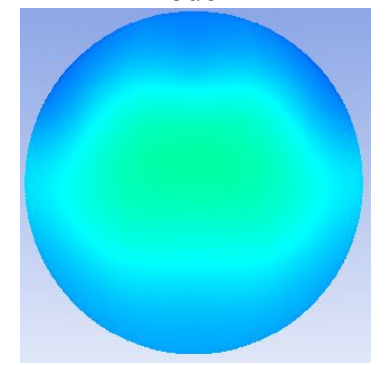

Model 5

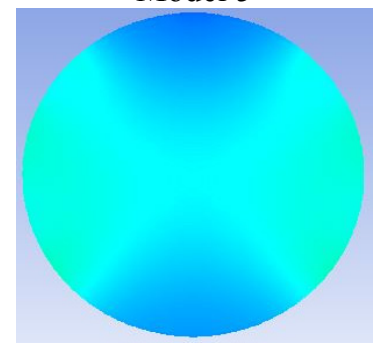

Model 8

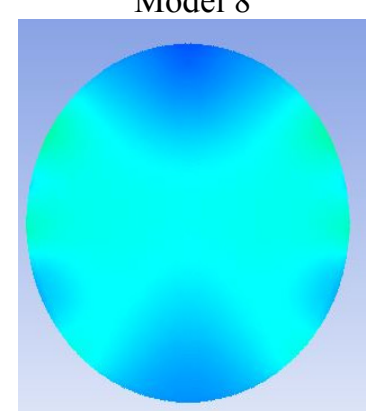

Model 11

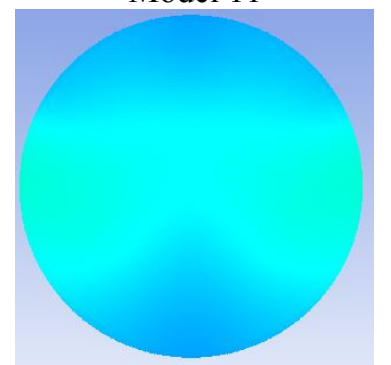

Model 14

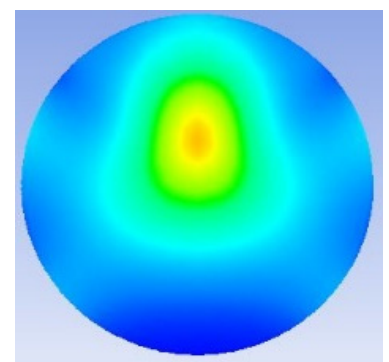

Model 3

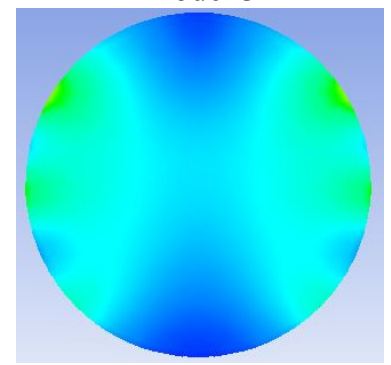

Model 6

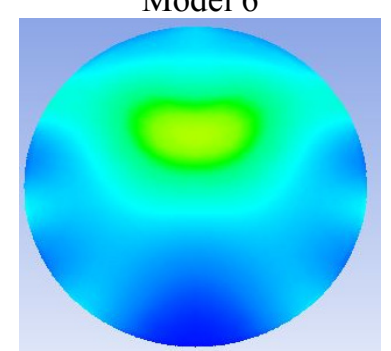

Model 9

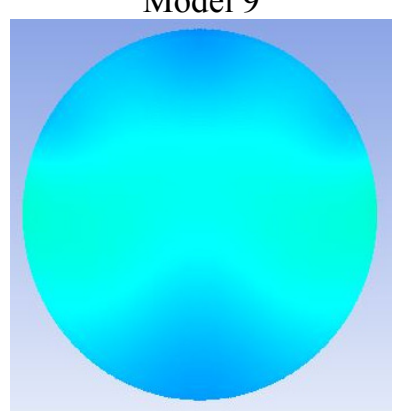

Model 12

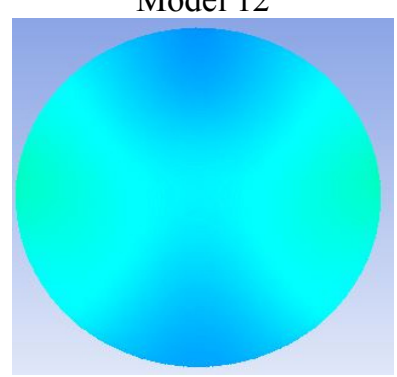

Model 15
Ch4.Mass Fraction Contour 1

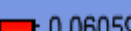

0.05744

0.05430

0.05115

0.04801

0.04487

0.04172

0.03858

0.03543

$-0.03229$

- 0.02914

$-0.02600$

$-0.02285$

$-0.01971$

- 0.01657

0.01342

0.01028

0.00713

0.00399

0.00084

H2.Mass Fraction

Contour 1

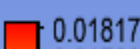

- 0.01723

0.01723

0.01629

$-0.01534$

$-0.01440$

0.01346

0.0125

0.01157

0.01063

0.00968

0.00874

0.00780

0.0068

0.00686
0.00591

0.00497

0.004

$-0.00403$

- 0.00308

0.00214

0.00120

Figure 17. Local methane mass fraction contour at outlet of the existing mixer and new mixer models (best case for each model) under Air-HCNG ratio 51.315.

\subsection{Verification of the CFD Results}

Model 7 was selected as the best model after considering the results of the homogeneity and propagation tests using ANSYS software on 15 models. The new mixer (Model 7) was tested practically 
and numerically (CFD) to validate the performance of the current mixer (air flow, fuel flow, AFR, and displacement of the valve) and the model (numerical model) that was built in ANSYS software.

The new mixer was studied for different engine speeds (1000-4000 rpm) and AFRCNG at 34.15, which represents $70 \%$ SR of diesel fuel with CNG fuel under a lambda value of 1 . This condition was achieved after stabilizing the boundary condition at the mixer inlets and outlet according to its corresponding engine speed. In the practical side, the new air-fuel mixer (Model 7) was fabricated based on the numerical analysis and also based on the new design for the movable mechanical mechanism which consist of small bevel gear, large bevel gear, power screw, valve, bolts and seals (Figure 18). AFR according to the engine speed and location of the valve were tested inside Model 7 by connecting it to mixer test rig (Figure 19). Moreover, the movement of the valve within the air-fuel mixer was examined by changing its position until the desired stoichiometric AFR of 34.15 was attained. The linear movement of the valve inside the mixer was controlled by using the rotary movement (hand movement) for the shaft. Moreover, the flow rate of the blower was set to specific engine speeds (1000-4000 rpm) so that the mass flow rate was controlled using a two-ball valve that was connected directly to the blower. In addition, the pressure in the CNG inlet of the new mixer was fixed through a pressure regulator depending on the maximum engine speed. In the numerical side, the same boundary condition at the mixer inlets and outlet in experimental test was used. The valve movement inside the air-fuel mixer was studied by changing its position until obtaining the suitable air-CNG ratio.

Figure 20 shows the relationship between the mixing air-fuel ratio and engine speed according to the experimental and numerical tests of the new mixer model (Model 7). A slight difference is observed between the experimental and numerical results of the air and fuel ratios corresponding to the engine speed within the acceptance limits of 3\% error ratio. Moreover, according to the numerical and experimental results for the AFR inside the new mixer, the air-CNG ratio is close to the stoichiometric AFR of 34.15.

Figure 21 and Table 7 show the comparison between the experimental and numerical results for AFRCNG inside the new mixer in terms of $\mathrm{CoV}$ and $R^{2}$. The $\mathrm{CoV}$ and $R^{2}$ obtained from the results of practical and numerical comparison for new mixer (i.e., 0.001494 and 0.96 , respectively) indicate good accuracy and consistency for the AFR values.

Figure 22 shows the relationship between the engine speed and valve displacement under different air-CNG ratios and constant pressure in the CNG inlet at the new mixer (25,395.63 Pa). The amount of air increases with increasing engine speed, and the valve displacement (forward) is increased to allow more fuel flow into the mixer. Thus, the required mixing ratios are achieved.

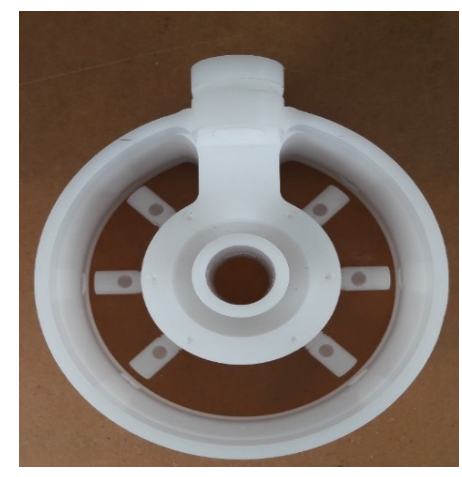

(a)

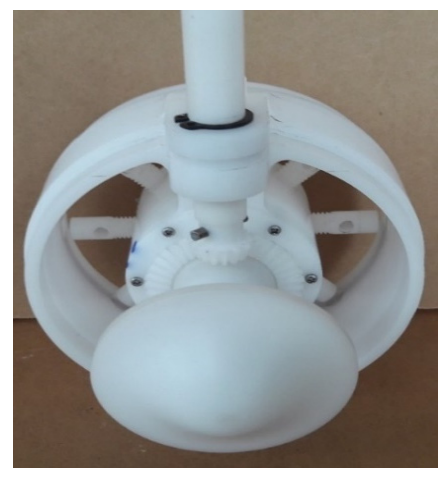

(b)

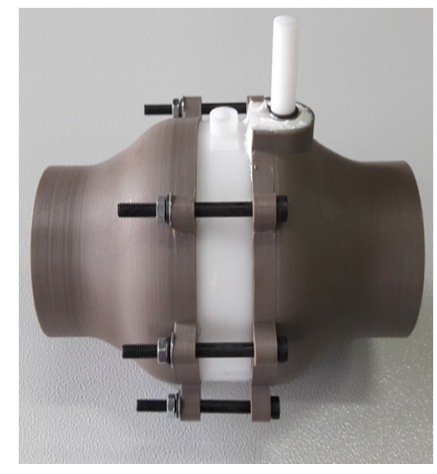

(c)

Figure 18. New mixer: (a) Main body of mixer; (b) The new mixer without covers; (c) The new mixer with covers. 


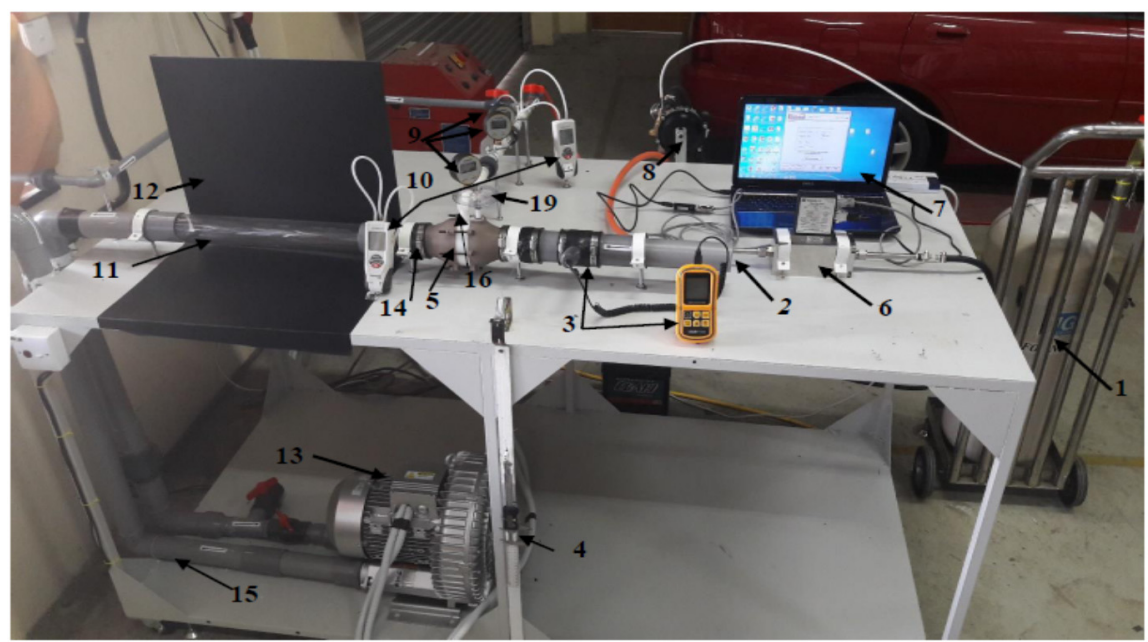

Figure 19. Photograph of the mixer test rig components from 1 to17 (CNG cylinder, air inlet, air mass flow meter, Vernier caliper, Mixer, CNG mass flow meter, Laptop, CNG pressure regulator, Pressure gauges, Manometer, Visible pipe, Black wall, Blower, Mixture outlet after mixer (CNG and Air), Mixture outlet after blower (CNG and Air), CNG inlet inside the mixer, and protractor, respectively).

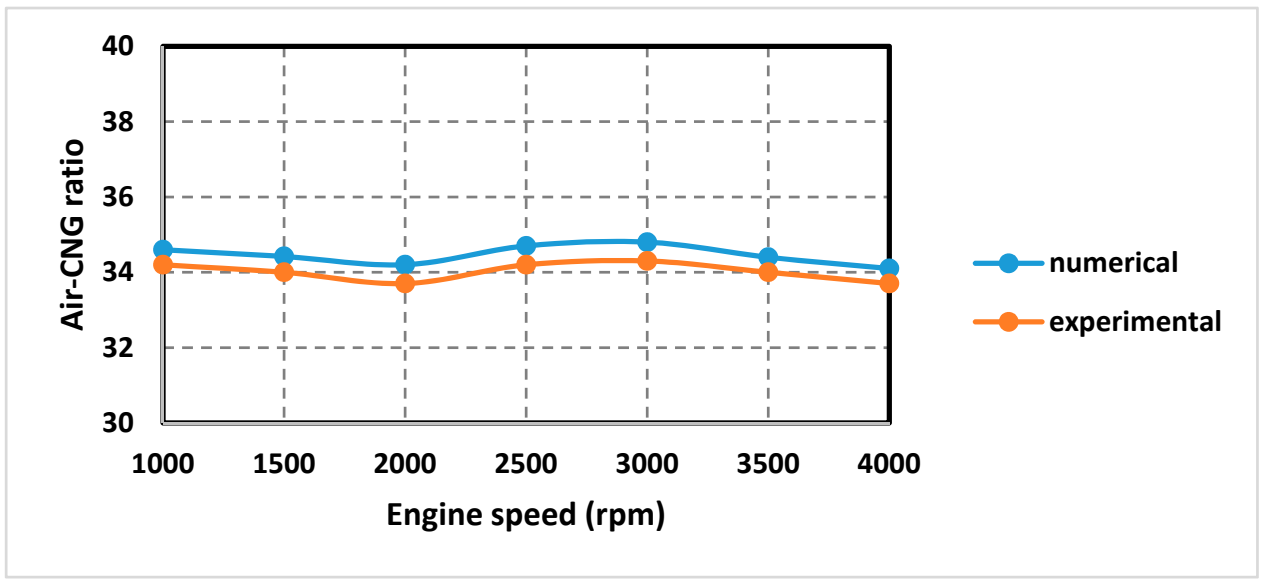

Figure 20. Variation of air-fuel ratio with engine speed according to numerical and experimental results for the new mixer model.

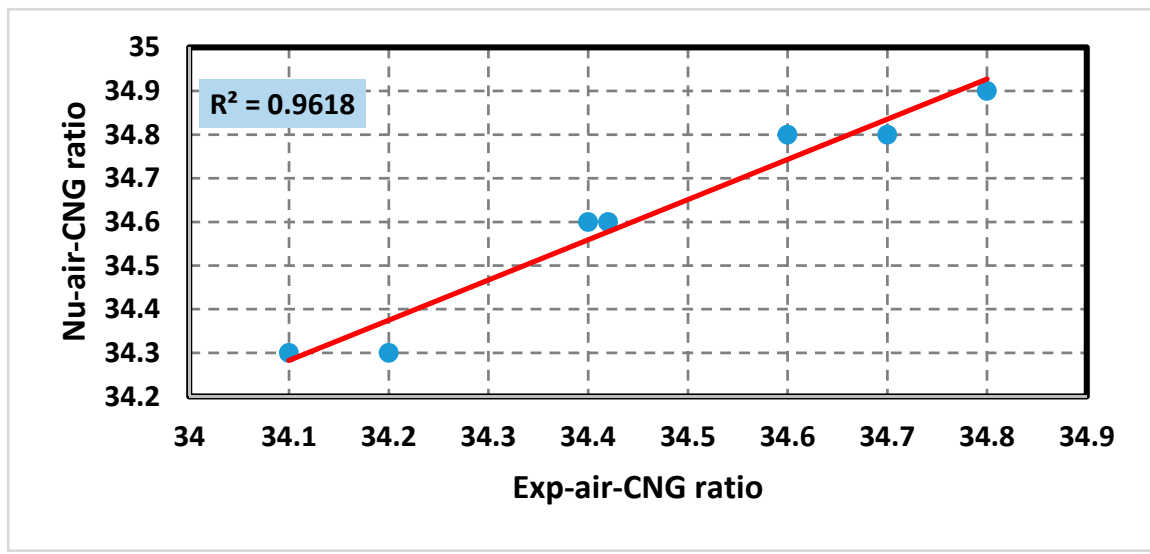

Figure 21. Comparison between the experimental and numerical results for air-CNG ratio inside the new mixer. 
Table 7. Comparison between the experimental and numerical results inside the new mixer.

\begin{tabular}{cccc}
\hline & Nu-Air-CNG Ratio & Exp-Air-CNG Ratio & Nu/Exp Ratio \\
\cline { 2 - 4 } & 34.6 & 34.8 & 0.994252874 \\
Statistical Parameters & 34.42 & 34.6 & 0.994797688 \\
& 34.2 & 34.3 & 0.997084548 \\
& 34.7 & 34.8 & 0.997126437 \\
& 34.8 & 34.9 & 0.99713467 \\
Mean & 34.4 & 34.6 & 0.994219653 \\
Standard Deviation & 34.1 & 34.3 & 0.994169096 \\
Coefficient Of Variation & 34.6 & 34.8 & 0.994252874 \\
\hline
\end{tabular}

Note: $\mathrm{Nu}$, refers to the numerical value and Exp, refers to the experimental value.

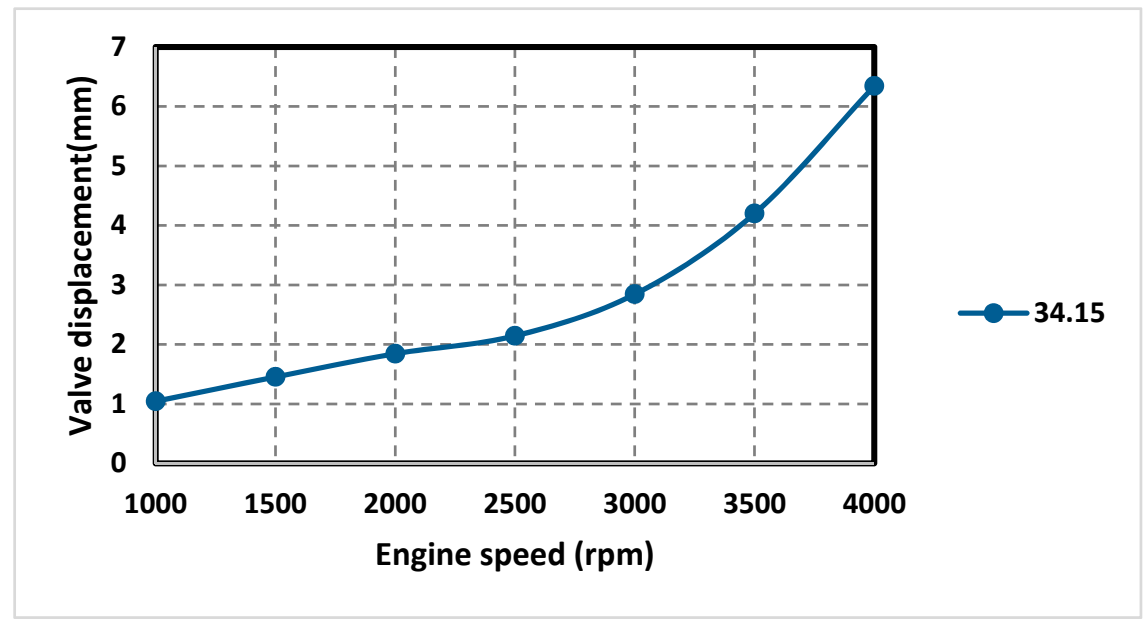

Figure 22. The relationship between the engine speed and valve displacement.

The YZ plan contour was used to study the distribution of the static pressure inside the new mixer model (Figure 23). At a constant engine speed, the highest static pressure appeared at the gas inlet. In addition, the pressure applied on the valve head is higher than the pressure behind the head. In addition, a variable distribution of pressure inside the new mixer is observed. Moreover, the engine speed and valve displacement significantly affect the pressure distribution inside the mixer. When the engine speed increases, the static pressure on the valve head increases while the pressure behind the valve decreases. Furthermore, when the valve moves forward, the fuel inlet area that is connected directly to the valve increases, thereby reducing the static pressure at the gas manifold inside the mixer.

Figure 24 explains the distribution of velocity (color contours) on the $\mathrm{YZ}$ plan inside the new mixer model. According to these figures, a changeable distribution of velocity occurs inside the mixer under different speeds, and valve displacements. In addition, at a constant engine speed, the velocity before the valve head is lower than that on the sides of the valve head. Moreover, the engine speed significantly affects the velocity distribution inside the mixer. That is, the amount of air increases as the engine speed increases, consequently increasing the air velocity [74]. Furthermore, when the valve moves forward, the fuel inlet area that is connected directly to the valve increases, thereby increasing the CNG velocity at the gas manifold inside the mixer. 


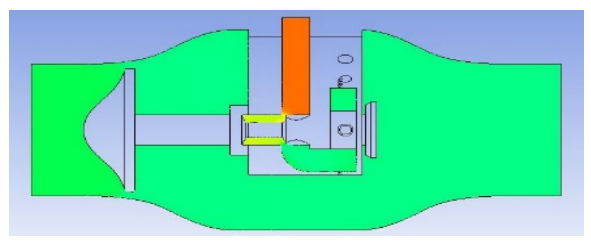

1000

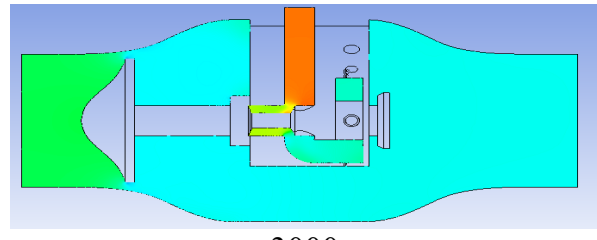

3000

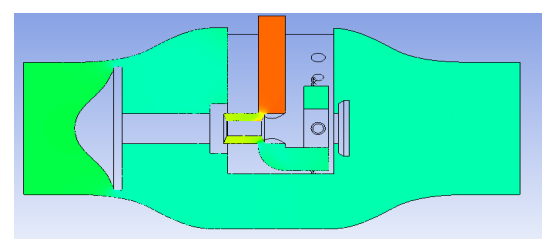

2000

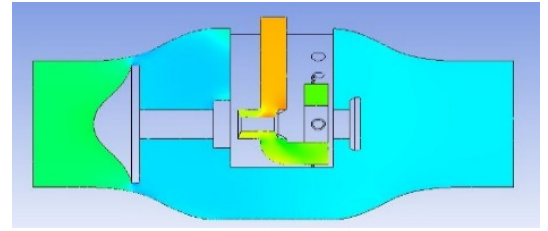

4000

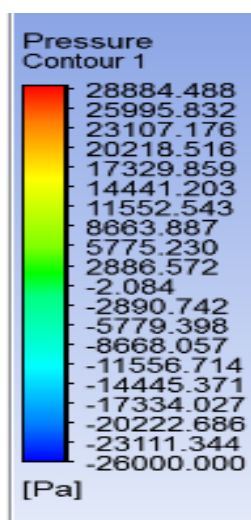

Figure 23. Distribution of static pressure on $Y Z$ plane inside the new mixer according to different engine speeds and constant air-CNG ratio (34.15).

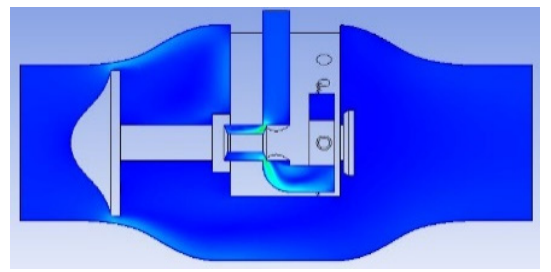

$1000 \mathrm{rpm}$

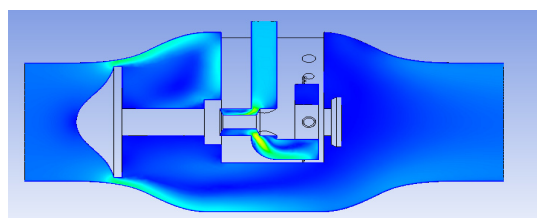

$3000 \mathrm{rpm}$

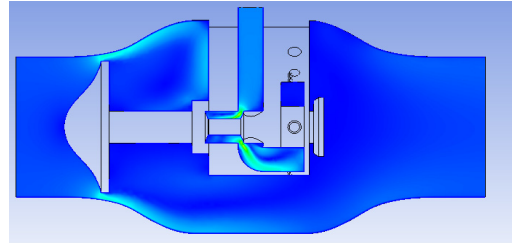

$2000 \mathrm{rpm}$

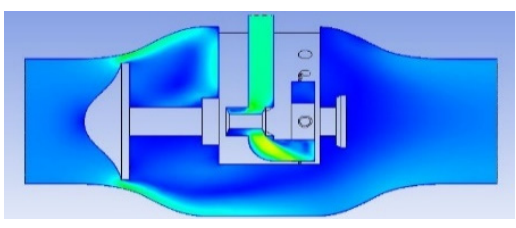

$3000 \mathrm{rpm}$

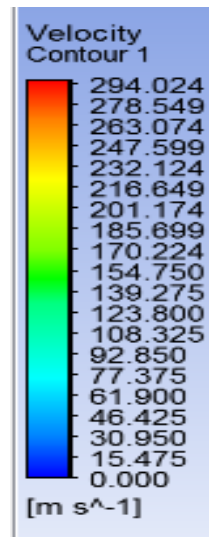

Figure 24. Distribution of velocity on $\mathrm{YZ}$ plane inside the new mixer according to different engine speeds and constant air-CNG ratio (34.15).

\section{Conclusions}

The major conclusions can be summarized as follows:

To overcome the heterogeneity problem for the gaseous fuel (CNG and HCNG) with air inside the diesel engine under different tri-fuel engine and dual-fuel engine modes, 15 mixer models were created to investigate the homogeneity and distribution of the mixture using ANSYS Workbench (CFD). The simulation results obtained under the maximum engine speed (4000 rpm) and full-open valve reveal that several parameters, such as the diameter, location, angle, and number of holes, affect the homogeneity and distribution of the mixture inside the mixer. Moreover, the best way to obtain a homogeneous mixing of the gaseous fuel (CNG and $\mathrm{HCNG}$ ) with air inside the mixer is to generate vortices and turbulent flow for the air and gaseous fuel inside the mixer. In addition, the gaseous fuel must be in direct contact with air to be able to mix properly. Moreover, prolonging the mixing time allows the efficient mixing of air and gaseous fuel in the longest possible period. However, the prolongation of mixing time is related directly to the nature of the flow. In specific, prolonging the mixing period does not affect the nature of the mixing if the flow is non-turbulent or no vortex is found inside the mixer. In addition, when the direction of the holes is with the direction of the airflow, increasing the distribution of the holes inside the mixer increases the gaseous fuel diffusion inside the mixer. Hence, the mixing process is improved. However, increasing the number of holes inside the mixer does not affect the gaseous fuel diffusion inside the mixer when the direction of holes is opposite 
that of the airflow. The simulation results reveal that the best UI values are obtained in models 7-8 and $12-15$, where the UI values under AFRHCNG $=51.31$ and AFRCNG $=34.15$ range between 0.9124 and 0.944. This result is due to the fact that the opposite direction of the holes with the airflow allows the generation of highly turbulent flow with vortices inside the mixer and the mixture of air with gaseous fuel for the longest possible time.

The new air-fuel mixer (Model 7) was fabricated based on the numerical analysis for ANSYS Workbench and also based on the new design for the movable mechanical mechanism. The new mixer was designed for easy maintenance and simple manufacturing of any part of the mixer so that each part of the mixer can be easily opened and assembled. According to the numerical and experimental results for the new mixer under different engine speeds (1000-4000) and air-CNG ratio of 34.15, a meaningful agreement is reached between the experimental and numerical values for AFRCNG $\left(R^{2}=0.96\right.$ and $\left.C o V=0.001494\right)$. This result confirms the validity of the numerical models that were built in ANSYS software.

Acknowledgments: The authors would like to express their gratitude to the support provided by the Universiti Putra Malaysia (UPM). The first author also acknowledges a scholarship program from the Ministry of Higher Education, Iraq.

Author Contributions: They advise and supervise me during writing the manuscript.

Conflicts of Interest: The authors declare no conflict of interest.

\section{References}

1. Yaliwal, V.; Banapurmath, N.; Gireesh, N.; Hosmath, R.; Donateo, T.; Tewari, P. Effect of nozzle and combustion chamber geometry on the performance of a diesel engine operated on dual fuel mode using renewable fuels. Renew. Energy 2016, 93, 483-501. [CrossRef]

2. Paul, A.; Panua, R.S.; Debroy, D.; Bose, P.K. An experimental study of the performance, combustion and emission characteristics of a CI engine under dual fuel mode using CNG and oxygenated pilot fuel blends. Energy 2015, 86, 560-573. [CrossRef]

3. Liu, J.; Zhang, X.; Wang, T.; Zhang, J.; Wang, H. Experimental and numerical study of the pollution formation in a diesel/CNG dual fuel engine. Fuel 2015, 159, 418-429. [CrossRef]

4. Wei, L.; Geng, P. A review on natural gas/diesel dual fuel combustion, emissions and performance. Fuel Process. Technol. 2016, 142, 264-278. [CrossRef]

5. Abagnale, C.; Cameretti, M.; De Simio, L.; Gambino, M.; Iannaccone, S.; Tuccillo, R. Numerical simulation and experimental test of dual fuel operated diesel engines. Appl. Therm. Eng. 2014, 65, 403-417. [CrossRef]

6. Zhang, C.-H.; Song, J.-T. Experimental study of co-combustion ratio on fuel consumption and emissions of NG-diesel dual-fuel heavy-duty engine equipped with a common rail injection system. J. Energy Inst. 2015, 89, 578-585. [CrossRef]

7. Chintala, V.; Subramanian, K. CFD analysis on effect of localized in-cylinder temperature on nitric oxide (NO) emission in a compression ignition engine under hydrogen-diesel dual-fuel mode. Energy 2016, 116, 470-488. [CrossRef]

8. Yang, Z.; Chu, C.; Wang, L.; Huang, Y. Effects of $\mathrm{H}_{2}$ addition on combustion and exhaust emissions in a diesel engine. Fuel 2015, 139, 190-197. [CrossRef]

9. Sancho Casarrubios, D. Modelling and CNG Distribution Study of a Natural Gas-Diesel Dual Fuel Engine. Master' Thesis, Lund University, Skane, Sweden, 2015.

10. Yang, B.; Xi, C.; Wei, X.; Zeng, K.; Lai, M.-C. Parametric investigation of natural gas port injection and diesel pilot injection on the combustion and emissions of a turbocharged common rail dual-fuel engine at low load. Appl. Energy 2015, 143, 130-137. [CrossRef]

11. Li, W.; Liu, Z.; Wang, Z. Experimental and theoretical analysis of the combustion process at low loads of a diesel natural gas dual-fuel engine. Energy 2016, 94, 728-741. [CrossRef]

12. Papagiannakis, R.; Kotsiopoulos, P.; Zannis, T.; Yfantis, E.; Hountalas, D.; Rakopoulos, C. Theoretical study of the effects of engine parameters on performance and emissions of a pilot ignited natural gas diesel engine. Energy 2010, 35, 1129-1138. [CrossRef] 
13. Maghbouli, A.; Saray, R.K.; Shafee, S.; Ghafouri, J. Numerical study of combustion and emission characteristics of dual-fuel engines using 3D-CFD models coupled with chemical kinetics. Fuel 2013, 106, 98-105. [CrossRef]

14. Mattarelli, E.; Rinaldini, C.A.; Golovitchev, V.I. CFD-3D analysis of a light duty Dual Fuel (Diesel/Natural Gas) combustion engine. Energy Procedia 2014, 45, 929-937. [CrossRef]

15. Egúsquiza, J.; Braga, S.; Braga, C. Performance and gaseous emissions characteristics of a natural gas/diesel dual fuel turbocharged and aftercooled engine. J. Braz. Soc. Mech. Sci. Eng. 2009, 31, 142-150. [CrossRef]

16. Papagiannakis, R.; Rakopoulos, C.; Hountalas, D.; Rakopoulos, D. Emission characteristics of high speed, dual fuel, compression ignition engine operating in a wide range of natural gas/diesel fuel proportions. Fuel 2010, 89, 1397-1406. [CrossRef]

17. Ott, T.; Onder, C.; Guzzella, L. Hybrid-electric vehicle with natural gas-diesel engine. Energies 2013, 6, 3571-3592. [CrossRef]

18. Arat, H.T.; Baltacioglu, M.K.; Özcanli, M.; Aydin, K. Effect of using Hydroxy-CNG fuel mixtures in a non-modified diesel engine by substitution of diesel fuel. Int. J. Hydrogen Energy 2016, 41, 8354-8363. [CrossRef]

19. Song, H.; Liu, C.; Li, F.; Wang, Z.; He, X.; Shuai, S.; Wang, J. A comparative study of using diesel and PODEn as pilot fuels for natural gas dual-fuel combustion. Fuel 2017, 188, 418-426. [CrossRef]

20. Wang, Z.; Zhao, Z.; Wang, D.; Tan, M.; Han, Y.; Liu, Z.; Dou, H. Impact of pilot diesel ignition mode on combustion and emissions characteristics of a diesel/natural gas dual fuel heavy-duty engine. Fuel 2016, 167, 248-256. [CrossRef]

21. Abdullah, S.; Kurniawan, W.H.; Shamsudeen, A. Numerical analysis of the combustion process in a compressed natural gas direct injection engine. J. Appl. Fluid Mech. 2008, 1, 65-86.

22. Semin, R.A.B. A technical review of compressed natural gas as an alternative fuel for internal combustion engines. Am. J. Eng. Appl. Sci 2008, 1, 302-311.

23. Demirbas, A. Methane Gas Hydrate; Springer Science \& Business Media: Londen, UK, 2010.

24. Khan, M.I.; Yasmin, T.; Shakoor, A. Technical overview of compressed natural gas (CNG) as a transportation fuel. Renew. Sustain. Energy Rev. 2015, 51, 785-797. [CrossRef]

25. Khan, M.I.; Yasmeen, T.; Khan, M.I.; Farooq, M.; Wakeel, M. Research progress in the development of natural gas as fuel for road vehicles: A bibliographic review (1991-2016). Renew. Sustain. Energy Rev. 2016, 66, 702-741. [CrossRef]

26. Bae, C.; Kim, J. Alternative fuels for internal combustion engines. Proc. Combust. Inst. 2017, 36, 3389-3413. [CrossRef]

27. Jia, Z; Denbratt, I. Effects of Natural Gas Percentage on Performance and Emissions of a Natural Gas/Diesel Dual-Fuel Engine. In Sustainable Automotive Technologies 2014; Springer Nature: New York, NY, USA, 2014; pp. 181-188.

28. Khan, M.I.; Yasmin, T.; Shakoor, A. International experience with compressed natural gas (CNG) as environmental friendly fuel. Energy Syst. 2015, 6, 507-531. [CrossRef]

29. Nithyanandan, K.; Lin, Y.; Donahue, R.; Meng, X.; Zhang, J.; Chia-fon, F.L. Characterization of soot from diesel-CNG dual-fuel combustion in a CI engine. Fuel 2016, 184, 145-152. [CrossRef]

30. Carlucci, A.; de Risi, A.D.; Laforgia, D.; Naccarato, F. Experimental investigation and combustion analysis of a direct injection dual-fuel diesel-natural gas engine. Energy 2008, 33, 256-263. [CrossRef]

31. Abdelaal, M.; Hegab, A. Combustion and emission characteristics of a natural gas-fueled diesel engine with EGR. Energy Convers. Manag. 2012, 64, 301-312. [CrossRef]

32. Zurbriggen, F.; Hutter, R.; Onder, C. Diesel-minimal combustion control of a natural gas-diesel engine. Energies 2016, 9, 58. [CrossRef]

33. De Morais, A.M.; Justino, M.A.M.; Valente, O.S.; de Morais Hanriot, S.; Sodré, J.R. Hydrogen impacts on performance and $\mathrm{CO}_{2}$ emissions from a diesel power generator. Int. J. Hydrogen Energy 2013, 38, 6857-6864. [CrossRef]

34. Szwaja, S.; Grab-Rogalinski, K. Hydrogen combustion in a compression ignition diesel engine. Int. J. Hydrogen Energy 2009, 34, 4413-4421. [CrossRef]

35. Alrazen, H.A.; Talib, A.A.; Adnan, R.; Ahmad, K. A review of the effect of hydrogen addition on the performance and emissions of the compression-Ignition engine. Renew. Sustain. Energy Rev. 2016, 54, 785-796. [CrossRef] 
36. Ghazal, O.H. Performance and combustion characteristic of CI engine fueled with hydrogen enriched diesel. Int. J. Hydrogen Energy 2013, 38, 15469-15476. [CrossRef]

37. Sandalc1, T.; Karagöz, Y. Experimental investigation of the combustion characteristics, emissions and performance of hydrogen port fuel injection in a diesel engine. Int. J. Hydrogen Energy 2014, 39, 18480-18489. [CrossRef]

38. Karagöz, Y.; Sandalcı, T.; Yüksek, L.; Dalkılıç, A. Engine performance and emission effects of diesel burns enriched by hydrogen on different engine loads. Int. J. Hydrogen Energy 2015, 40, 6702-6713. [CrossRef]

39. Deb, M.; Sastry, G.; Bose, P.; Banerjee, R. An experimental study on combustion, performance and emission analysis of a single cylinder, 4-stroke DI-diesel engine using hydrogen in dual fuel mode of operation. Int. J. Hydrogen Energy 2015, 40, 8586-8598. [CrossRef]

40. Karagöz, Y.; Güler, İ.; Sandalcı, T.; Yüksek, L.; Dalkılıç, A.S. Effect of hydrogen enrichment on combustion characteristics, emissions and performance of a diesel engine. Int. J. Hydrogen Energy 2016, 41, 656-665. [CrossRef]

41. Yadav, V.S.; Soni, S.; Sharma, D. Engine performance of optimized hydrogen-fueled direct injection engine. Energy 2014, 65, 116-122. [CrossRef]

42. Zhou, J.; Cheung, C.; Zhao, W.; Leung, C. Diesel-hydrogen dual-fuel combustion and its impact on unregulated gaseous emissions and particulate emissions under different engine loads and engine speeds. Energy 2016, 94, 110-123. [CrossRef]

43. Köse, H.; Ciniviz, M. An experimental investigation of effect on diesel engine performance and exhaust emissions of addition at dual fuel mode of hydrogen. Fuel Process. Technol. 2013, 114, 26-34. [CrossRef]

44. Zhou, J.; Cheung, C.; Leung, C. Combustion, performance and emissions of a diesel engine with $\mathrm{H}_{2}, \mathrm{CH}_{4}$ and $\mathrm{H}_{2}-\mathrm{CH}_{4}$ addition. Int. J. Hydrogen Energy 2014, 39, 4611-4621. [CrossRef]

45. Choi, G.H.; Chung, Y.J.; Han, S.B. Performance and emissions characteristics of a hydrogen enriched LPG internal combustion engine at 1400rpm. Int. J. Hydrogen Energy 2005, 30, 77-82. [CrossRef]

46. Saravanan, N.; Nagarajan, G. An experimental investigation of hydrogen-enriched air induction in a diesel engine system. Int. J. Hydrogen Energy 2008, 33, 1769-1775. [CrossRef]

47. Alrazen, H.A.; Talib, A.A.; Ahmad, K. A two-component CFD studies of the effects of $\mathrm{H}_{2}, \mathrm{CNG}$, and diesel blend on combustion characteristics and emissions of a diesel engine. Int. J. Hydrogen Energy 2016, 41, 10483-10495. [CrossRef]

48. Zhou, J.; Cheung, C.; Leung, C. Combustion and emission of a compression ignition engine fueled with diesel and hydrogen-methane mixture. In Proceedings of the World Academy of Science, Engineering and Technology Conference, Amsterdam, The Netherlands, 8-9 August 2013; pp. 107-112.

49. Karagöz, Y.; Güler, İ.; Sandalcı, T.; Yüksek, L.; Dalkılıç, A.S.; Wongwises, S. Effects of hydrogen and methane addition on combustion characteristics, emissions, and performance of a CI engine. Int. J. Hydrogen Energy 2016, 41, 1313-1325. [CrossRef]

50. Pichayapat, K.; Sukchai, S.; Thongsan, S.; Pongtornkulpanich, A. Emission characteristics of using HCNG in the internal combustion engine with minimum pilot diesel injection for greater fuel economy. Int. J. Hydrogen Energy 2014, 39, 12182-12186. [CrossRef]

51. Yusaf, T.; Yusoff, M.Z. Development of a 3D CFD Model to Investigate the Effect of the Mixing Quality on the CNG-Diesel Engine Performance. In Proceedings of the International Conference and Exhibition and Natural Gas Vehicles, Yokohama, Japan, 17-19 October 2000; International Association of Natural Gas Vehicles (IANGV): Yokohama, Japan.

52. Gorjibandpy, M.; Sangsereki, M.K. Computational investigation of air-gas venturi mixer for powered bi-fuel diesel engine. World Acad. Sci. Eng. Technol. 2010, 4, 1197-1201.

53. Dahake, M.; Patil, S.; Patil, S. Performance and Emission Improvement through Optimization of Venturi Type Gas Mixer for CNG Engines. Int. Res. J. Eng. Technol. 2016, 3, 994-999.

54. Chintala, V.; Subramanian, K. A CFD (computational fluid dynamics) study for optimization of gas injector orientation for performance improvement of a dual-fuel diesel engine. Energy 2013, 57, 709-721. [CrossRef]

55. Supee, A.; Shafeez, M.; Mohsin, R.; Majid, Z. Performance of Diesel-Compressed Natural Gas (CNG) Dual Fuel (DDF) Engine via CNG-Air Venturi Mixjector Application. Arab. J. Sci. Eng. 2014, 39, 7335-7344. [CrossRef]

56. Wong, W.L. Compressed Natural Gas as an Alternative Fuel in Diesel Engines. Bachelor's Thesis, University of Southern Queensland, Toowoomba, Queensland, Australia, 2005. 
57. Hussain, J.; Palaniradja, K.; Algumurthic, N.; Manimarana, R. Diesel Engine Emissions and After Treatment Techniques-A Review. J. Eng. Res. Stud. 2012, 3, 34-44.

58. Reşitoğlu, İ.A.; Altinişik, K.; Keskin, A. The pollutant emissions from diesel-engine vehicles and exhaust aftertreatment systems. Clean Technol. Environ. Policy 2015, 17, 15-27. [CrossRef]

59. Mohsin, R.; Yaacob, Z.; Chang, Y. Review of mixture formation unit for CNG motorcycle. J. Chem. Nat. Resour. Eng. 2008, 2, 1-7.

60. Mohsin, R.; Yaacob, Z.; Chang, Y. Computational fluid dynamics analysis of an injection mixer for CNG engines simulation. J. Teknol. 2008, 49, 297-310.

61. Chang, Y.S.; Yaacob, Z.; Mohsin, R. Computational Fluid Dynamics Simulation of Injection Mixer for CNG Engines. In Proceedings of the World Congress on Engineering and Computer Science (WCECS 2007), San Francisco, CA, USA, 24-26 October 2007.

62. Kadirgama, K.; Noor, M.; Rahim, A.; Devarajan, R.; Rejab, M.; NM, N.Z. Design and Simulate Mixing of Compressed Natural Gas with Air in a Mixing Device. In Proceedings of the MUCET2008, Malaysian Technical Universities Conference on Engineeringand Technology, Putra Palace, Perlis, Malaysia, 15-16 March 2008.

63. Danardono, D.; Kim, K.-S.; Lee, S.-Y.; Lee, J.-H. Optimization the design of venturi gas mixer for syngas engine using three-dimensional CFD modeling. J. Mech. Sci. Technol. 2011, 25, 2285-2296. [CrossRef]

64. Noor, M.; Wandel, A.P.; Yusaf, T. Detail guide for CFD on the simulation of biogas combustion in bluff-body mild burner. In Proceedings of the 2nd International Conference of Mechanical Engineering Research (ICMER 2013), Bukit Gambang Resort City, Kuantan, Pahang, Malaysia, 1-3 July 2013; pp. 1-25.

65. Sumner, J.; Watters, C.S.; Masson, C. CFD in wind energy: The virtual, multiscale wind tunnel. Energies 2010, 3, 989-1013. [CrossRef]

66. Bora, B.J.; Debnath, B.K.; Gupta, N.; Sahoo, N.; Saha, U. Investigation on the flow behaviour of a venturi type gas mixer designed for dual fuel diesel engines. Int. J. Emerg. Technol. Adv. Eng. 2013, 3, 202-209.

67. Johansson, K. Numerical Simulation of Fuel Filling with Volume of Fluid. Master's Thesis, Chalmers University Of Technology, Gothenburg, Sweden, 2011.

68. Ekaterinaris, J.A. High-order accurate, low numerical diffusion methods for aerodynamics. Prog. Aerosp. Sci. 2005, 41, 192-300. [CrossRef]

69. Fluent Inc. FLUENT 6.3 User's Guide; Fluent Inc.: Canonsburg, PA, USA, 2006.

70. Martínez-Martínez, S.; Leal-Garza, R.D.; Sánchez-Cruz, F.A.; Villarreal, E.B.; Amado-Covarrubias, M. CFD analysis of the effect of the exhaust manifold design on the close-coupled catalytic converter performance. J. KONES 2010, 17, 303-311.

71. Abo-Serie, E.; Özgur, M.; Altinsik, K. Computational analysis of methane-air venturi mixer for optimum design, In Proceedings of the 13th International Combustion Symposium, Bursa, Turkey, 9-11 September 2015.

72. Kim, J.; Kim, H.; Yoon, S.; Sa, S. Effect of intake valve swirl on fuel-gas mixing and subsequent combustion in a CAI engine. Int. J. Automot. Technol. 2008, 9, 649-657. [CrossRef]

73. Singh, R.; Maji, S. Dual fueling of a twin-cylinder compression ignition engine with diesel and CNG. J. Eng. Appl. Sci. 2012, 7, 90-99. [CrossRef]

74. Ramasamy, D.; Samykano, M.; Kadirgama, K. Design Of Compressed Natural Gas Mixer Using Computational Fluid Dynamics. In Proceedings of the National Conference in Mechanical Engineering Research and Postgraduate Students, UMP, Kuantan, Pahang, Malaysia, 26-27 May 2010; pp. 614-620.

(C) 2017 by the authors. Licensee MDPI, Basel, Switzerland. This article is an open access article distributed under the terms and conditions of the Creative Commons Attribution (CC BY) license (http://creativecommons.org/licenses/by/4.0/). 